\title{
VALUE OF INVESTORS' ESCALATION OF COMMITMENT IN PPP PROJECTS USING REAL OPTION THINKING
}

\author{
Ruolan GAO, Jicai LIU (1)* \\ School of Economics and Management, Southwest Jiaotong University, Chengdu, China
}

Received 09 July 2019; accepted 19 December 2019

\begin{abstract}
Escalation of commitment (EOC) is a common behavior among investors who receive negative feedback (NF) in public-private partnership (PPP) projects, and this behavior typically leads to sizable losses. Recognizing this, investors set a mental threshold and track investments for escalation. Once losses reach the threshold, investors will terminate the escalation behavior, namely, they will transfer projects to governments to obtain compensation or residual asset value. This paper analyzes the maximum amount of NF that investors can sustain based on a belief-adjustment model, followed by the analysis of the greatest loss degree. Then, a threshold model for EOC is constructed using real option thinking. Different from the usual judgment criteria of the traditional option method, the threshold is less than zero in the EOC scenario. The results show that the threshold correlates with the initial generative cognition, the sunk cost level, the degree of the government guarantee and investors' behavioral preferences as well as with total investment and return on investment. These findings serve as a reference for governments to de-escalate investors' commitment in PPP projects.
\end{abstract}

Keywords: public-private partnership projects, escalation of commitment, real option theory, threshold, abandonment option, early termination pricing.

\section{Introduction}

Public-private partnership (PPP) schemes have been widely applied worldwide in many fields, such as toll roads, water plants and energy infrastructure (e.g., Biygautane et al., 2019; Carbonara \& Pellegrino, 2018, 2019; Feng et al., 2015; Osei-Kyei \& Chan, 2018; Song et al., 2015; Valipour et al., 2019; Villani et al., 2017). Despite the advantages of PPP arrangements, private investors are assuming great risks and uncertainties due to the large scale of investment and long payback period (Liu et al., 2014); consequently, they may often require mitigation of these risks through guarantees provided by governments to compensate for possible private losses (Carbonara \& Pellegrino, 2018; Liu et al., 2019b; Pellegrino et al., 2019; Zapata Quimbayo et al., 2019). Nevertheless, investors often receive negative feedback (NF) in PPP projects such as low market payoffs, schedule delays and budget overruns, implying that these projects are likely to fail (Zhang et al., 2003). In this context, one of the most frustrating decisions that investors must make is whether to continue projects in the face of uncertain prospects (Keil et al., 2000). Sometimes, to maintain their own reputation and retrieve losses, investors choose to continue by escalating commitment in response to sunk costs (including considerable past efforts and major existing investments) in social-economic activities (Hafenbrädl \& Woike, 2018; Staats et al., 2018), such as the Denver International Airport (Montealegre \& Keil, 2000). Such irrational behavior is a general phenomenon known as escalation of commitment (EOC) (Staw, 1976). EOC by private investors is also a common behavioral trap in PPP projects. For example, in the Taraso Fukuoka project, estimates of the number of project users were overoptimistic, and when faced with the low actual income, investors revised the project's facilities, operating methods and content, and also replaced the external operating companies to reverse the situation, which despite their efforts ended in bankruptcy (Song et al., 2018). Similarly, when the Channel Fixed Link and Quanzhou Citong Bridge encountered operational difficulties, investors extended the schedule and budget, only to find themselves trapped, leading to an enormous waste of resources and substantial losses for project stakeholders and even the public (Song et al., 2018; Winch, 2013). EOC by investors not only results in an increase in project risks and a decline in performance but also leads to project failure in severe cases (Feldman \& Wong, 2018).

*Corresponding author. E-mail: jicailiu@126.com 
However, EOC is not a robust phenomenon and typically occurs only in the early stages of PPP projects when investors are attempting to interpret NF (McCain, 1986). With the increased NF, projects are likely to fail more obviously, and the losses borne by investors also increase. Once losses accumulate to a certain extent (the so-called threshold), investors will terminate their EOC, thereby abandoning projects and transferring them to governments to receive some compensation or residual asset value. Investors usually have the right, but no obligation, to require governments to take over projects in advance as initially agreed, which can be defined as an abandonment option and also a put option (Xiong et al., 2015). In real option theory, investors are assumed to make decisions from a rational and probabilistic perspective (Garvin \& Ford, 2012). Nevertheless, this assumption is not always tenable, for instance, when considering managerial behavior such as EOC (Herder et al., 2011; Triantis, 2005). Investors may preclude the exercise of the abandonment option due to personal incentives (such as a promotion), even when that choice might be optimal for them, i.e., when the project value with option is zero (Dahan \& Mendelson, 2001). Different from traditional real option theory, in an EOC scenario, the critical condition whereby investors terminate PPP projects is no longer that the project value is equal to zero; instead, some losses are acceptable, namely, the termination threshold is less than zero.

The escalation behavior of investors is a vital and complex issue. Decades of research have explained EOC from different perspectives, such as cognitive dissonance theory (Festinger, 1962), psychological commitment theory (Kiesler, 1971), self-justification theory (Staw, 1976), mental budgeting theory (Heath, 1995) and prospect theory (Kahneman \& Tversky, 1979). EOC is determined by various factors, such as sunk costs (Chung \& Cheng, 2018; Keil et al., 1995; Moon, 2001; Staats et al., 2018), guarantees (Zardkoohi, 2004), information asymmetry (Berg et al., 2009), self-esteem (Schaumberg \& Wiltermuth, 2014), anticipated regret (Sarangee et al., 2019; Wong \& Kwong, 2007), ego depletion (Lee et al., 2018), paradox mindset (Wong \& Kwong, 2018), reward and punishment mechanism (Liu et al., 2019a), the decision responsibility and decision-maker involved (Boulding et al., 2016), competitors (Hsieh et al., 2015), risk preferences (Whyte, 1986) and cultural backgrounds (Drummond, 2014). Conclusively, current studies on EOC have focused on theoretical explanations and influential determinants while remaining relatively silent on the threshold for investors' EOC.

Therefore, the aim of this paper is to construct a threshold model of investors' EOC in PPP projects using real option thinking to present the maximum losses that investors can sustain. The findings will serve as a reference for governments to de-escalate investors' commitment. The remainder of this paper is organized as follows. First, a comprehensive literature review on EOC and real option theory is presented. Next, a belief-adjustment model is constructed to illustrate the maximum amount of NF that investors can sustain, and then a real option model of the threshold for investors' EOC is developed, followed by model analysis and discussions. A numerical example is then provided to illustrate the feasibility and application of these models. Finally, this paper concludes with a summary of the findings and recommendations for the de-escalation of commitment.

\section{Literature review}

\subsection{Escalation of commitment (EOC)}

EOC, first proposed by Staw (1976), is a common but irrational phenomenon in decision-making (Chung \& Cheng, 2018; Sleesman et al., 2018; Wong \& Kwong, 2018). Three typical features in an EOC scenario have been defined: sunk costs such as money, time and even self-identities have been invested; investors have received NF about projects; and investors must decide whether to continue investing or to completely withdraw from projects (i.e., quit investing) (Brockner, 1992; Jani, 2011).

Many theories have been proposed to explain such behavior. Couched originally in cognitive dissonance theory by Festinger (1962) and psychological commitment theory by Kiesler (1971), investors develop a generative cognition toward the initial decision when investing in a PPP project, meaning a belief that the expected project profits will be realized (Festinger, 1962). As the project proceeds, if the subsequent feedback is inconsistent with the generative cognition (e.g., policy changes make it difficult to maintain project performance, and thus the project should be abandoned), dissonant cognition arises, which refers to the psychological conflict when real-world situation contradicts the psychological ideas or assumptions (Festinger, 1962). In such a case, investors will re-evaluate the project to reduce and even eliminate the discomfort brought about by the dissonant cognition. If generative cognition exceeds dissonant cognition, investors will continue to invest, and EOC will prevail in PPP projects. Derived from cognitive dissonance theory and psychological commitment theory, Staw (1976) proposed self-justification theory, which holds that investors make certain decisions based on the expected positive outcomes. When receiving NF, investors are unwilling to admit that their previous decisions were incorrect, and therefore will persist in their commitments to those decisions to maintain their internal and external justification (Bobocel \& Meyer, 1994; Brockner, 1992; Staw, 1981). In addition, prospect theory claims that investors manifest risk-seeking behavior when faced with a prospect of losses upon being presented with NF (Kahneman \& Tversky, 1979). The mental budgeting reveals that only when the losses arising from EOC reach investors' threshold will they terminate EOC and abandon projects (Heath, 1995).

From an approach-avoidance perspective, Pan et al. (2009) presented an integrated theoretical process model for identifying, describing, and analyzing complex escala- 
tion phenomena. Project management constructs also play an important role in escalation (Keil et al., 2003). Additionally, organizational climate and information asymmetry in individualistic and collectivistic culture are both important determinants (Tan et al., 2003). In practice, escalation could be viewed as an approach to avoiding conflicts (Pan et al., 2006). Escalation behavior is driven by many determinants. Typically, EOC involves the interplay of four sets of forces over time (Ross \& Staw, 1993). Under this rubric, project determinants are objective aspects of a project, such as the sunk cost (Chung \& Cheng, 2018; Moon, 2001; Staats et al., 2018), guarantees (Zardkoohi, 2004), information asymmetry (Berg et al., 2009), reward and punishment mechanism (Liu et al., 2019a), and salvage value (Ross \& Staw, 1993). The psychological determinants mainly refer to personalities, emotional elements and cognitive styles of investors, including selfesteem (Schaumberg \& Wiltermuth, 2014), ego depletion (Lee et al., 2018), neuroticism (Moon et al., 2003b), anticipated regret (Sarangee et al., 2019; Wong \& Kwong, 2007), paradox mindset (Wong \& Kwong, 2018), risk preference (Whyte, 1986) and rational thinking style (Wong et al., 2008). Organizational determinants embrace such variables as political supports within an organization, including the decision responsibility and decision-maker involved (Boulding et al., 2016), the agency (Sleesman et al., 2012), the group decision process and incrementalism (Moon et al., 2003a) etc. In terms of social determinants, this category contains interpersonal processes, reflecting the social, political, economic and cultural environment that may result in excess commitment, for instance, competitors (Hsieh et al., 2015), and cultural backgrounds (Drummond, 2014). In a nutshell, all of these works offer a theoretical basis for reducing this irrational behavior.

\subsection{Real option theory}

Real option theory evolves from financial option. By definition, real option is a right, not an obligation, to buy or sell real assets only when profitable (Bloom, 2009). Similar to financial options, real option holders can execute the option at a fixed price agreed upon by both parties, which is called a strike price and usually stipulated in the contract. Quite simply, there are two basic types of real options: call and put options. In call options, the owners have the right to purchase when the market price of an asset is higher than the strike price, whereas in put options, the owners can execute the right to sell at the strike price even when it exceeds the market price. From the perspective of option execution time, if an option can only be exercised on the expiration date agreed upon previously, it is known as a "European option"; otherwise, if it can be exercised at any time prior to the expiration date, it is known as an "American option". In practical projects, real options can be categorized into many different types including growth options and abandonment options etc. (Martins et al., 2013; Nunes \& Pimentel, 2017).
Real option theory is well known for capitalizing on uncertainties and risks through strategic investments and contracts (Brouthers \& Dikova, 2010; Buyukyoran \& Gundes, 2018; Li et al., 2017; Morreale et al., 2017; Trigeorgis \& Tsekrekos, 2018). Thus, option thinking can be used to proactively design and manage strategic investments (Attarzadeh et al., 2017; Galera \& Soliño, 2010). In general, the investment value of projects increases in the consideration of managerial flexibility (Aretz \& Pope, 2018). That is, the potential execution of options adds some additional values to projects that cannot be easily captured using traditional procedures. Due to the irreversibility of investment projects and the uncertainty of future payoffs, Guo et al. (2019) proposed an optimal scheme for energy performance contracting through the incorporation of real option analysis. When facing uncertainties (e.g., energy price and policy fluctuations), real option theory can be used to conduct project evaluation to address the issue of investment decisions (Yao et al., 2019). Likewise, timeto-build investments could be predicted to be delayed over future revenue (Oh \& Yoon, 2020). Simultaneously considering the option to defer and the option to abandon, Yu et al. (2019) constructed a real option model for geothermal heating investment decision-making that incorporates carbon trading and resource taxes.

To date, real option theory has been widely applied worldwide to evaluate government guarantees and provide supports to mitigate the risks of PPP projects (Collan et al., 2016). Cruz and Marques (2013) addressed contract flexibility and its incorporation into PPP arrangements through a proposed double entry matrix. In fact, there are many forms of guarantees for different risks in PPP projects. For instance, an intensive study on maximum interest rate guarantees revealed that the optimal value of the interest rate cap could be set through real options (Pellegrino et al., 2019). In a study examining a restrictive agreement, Liu et al. (2014) employed a real option approach to determine the value of restrictive competition guarantees. Using PPP rental retirement villages as an example, Liu et al. (2019b) explained compensation and guarantee costs while considering benefit redistribution when governments are unable to keep their promises regarding guarantee provision. With a focus on toll road infrastructure, the implications of PPP agreements for the execution of expansion options were examined by Krüger (2012) to promote a social optimal outcome. Treating traffic as the underlying asset from a real option perspective, an estimate of the minimum traffic guarantee value can be obtained (Galera \& Soliño, 2010); and subsequently, the risk-allocation mechanisms can be formulated (Brandão et al., 2012). Moreover, the binomial lattice has proven to be a valid tool to obtain a more robust and comprehensive model for PPP projects (Jeong et al., 2015).

Additionally, minimum revenue guarantees (MRGs) are also granted to increase the viability and reduce the risks of PPP projects (Wang et al., 2019). Marzouk and 
Ali (2018) identified MRG values under a mix of contractual conditions. However, evaluations of such government guarantees using the real options approach often make the basic assumption that traffic volume follows a geometric Brownian motion, and this assumption is not always tenable. By applying statistical tests to check the validity of this assumption, Zapata Quimbayo et al. (2019) innovatively showed how toll road traffic can be modelled under alternate models to define the fair value of MRGs secured by governments. To avoid excessive guarantees to place an increased burden on the public budget, both the optimum upper and lower boundaries of compound MRG and maximum revenue cap (MRC) options should be identified, which helps to establish a fair risk allocation structure and further create a winwin contract (Ashuri et al., 2011; Buyukyoran \& Gundes, 2018; Carbonara \& Pellegrino, 2018). In application, the combination integration of real options and other advanced techniques, e.g., continuous stochastic approaches, is conducive to developing a more efficient valuation approach to reserve budget for government guarantees (Almassi et al., 2012). In short, real option theory is an efficient way to analyze government guarantees and mitigate PPP risks.

\subsection{Relationship between EOC and real options}

In PPP projects, instead of transferring projects to governments, investors are often likely to escalate their commitment in response to NF given the considerable efforts and financial resources they have invested, typically allowing some degree of losses for themselves. Nonetheless, since EOC generates major losses for investors, such behavior will disappear once the level of NF and the losses reach a threshold beyond what investors can sustain. At this point, investors will exercise their abandonment option by terminating the commitment to PPP projects and transfer the projects to governments to recover the salvage value and avoid further losses (Xiong et al., 2015). In cases where potential losses are relatively small, the option to abandon is virtually worthless, and early EOC may, counterintuitively, provide a strategic advantage (Dahan \& Mendelson, 2001).

The abandonment option requires investors to acquire the ability to abandon a current operation permanently (Martins et al., 2013). Exactly in PPP projects, due to the embedded uncertainties and risks, investors typically own the right to require governments to take over the project as initially agreed in advance in cases where the project construction or operation cannot be maintained continuously, but with no obligations accordingly (Iossa et al., 2007). Especially in an escalation scenario of PPP projects with poorer performance, private investors can abandon and withdraw from these projects at any time. In this sense, the early termination right held by investors is an American put option (Liu et al., 2017).

\subsection{Research questions}

As EOC may entail a considerable waste of resources for both investors and the public, de-escalation of commitment potentially presents a more important issue than escalation to some degree (G. Pan \& S. L. Pan, 2011). In an EOC scenario, decisions can be deemed progress decisions and require temporal elements (Moon, 2001). Although government guarantees are typically in place during cooperation of PPP projects, early termination may be inevitable with sequential NF and the integration of multiple determinants. Private investors need to make a series of decisions, including the degree of losses and early termination (Schaumberg \& Wiltermuth, 2014; Staw \& Ross, 1989). Nevertheless, the vast majority of prevailing studies have been devoted to theoretical explanations and different determinants of EOC, but few studies analyze the termination threshold and project value for investors' EOC in PPP projects. From the perspective of real option theory, prior studies have focused on external facts, such as the minimum demand guarantee and MRG, while ignoring the behavior of private investors in PPP projects. More importantly, the relationship between the escalation behavior of investors in PPP projects and real options has been overlooked. Indeed, the early termination right of private investors that can be exercised at any time to transfer the project to governments is an option to abandon and an American put option.

To bridge the gaps in the extant literature, this paper incorporates such escalation behavior of private investors into the real option model. Specifically, the research questions include two parts: one is to identify the termination threshold for investors' EOC in view of the peculiarity of PPP projects, and the other is to illustrate the project value with an abandonment option in the EOC scenario. The main contributions of this paper are to analyze the subjective escalation behavior of investors in PPP projects and then incorporate this behavior into the real option model. As a result, the critical condition for investors' escalation termination is different from that in traditional real option theory, and it is no longer the case that the value of a project with an option is zero; instead, some losses are allowable, namely, the threshold is less than zero. The findings can serve as a reference for both governments and investors to collectively curb potential escalation behavior and work toward improving governance efficiency in PPP projects.

\section{Modeling and solutions}

\subsection{Option modeling with EOC in PPP projects}

When receiving NF regarding PPP projects, according to real option theory, investors should terminate projects immediately once the project value including expanded value is zero. Despite this logic, investors still opt to persist in projects, which means EOC occurs. Meanwhile, investors presuppose a psychological threshold (denoted by $V_{\text {low }}$ ) and will track investments for escalation. Once the losses 


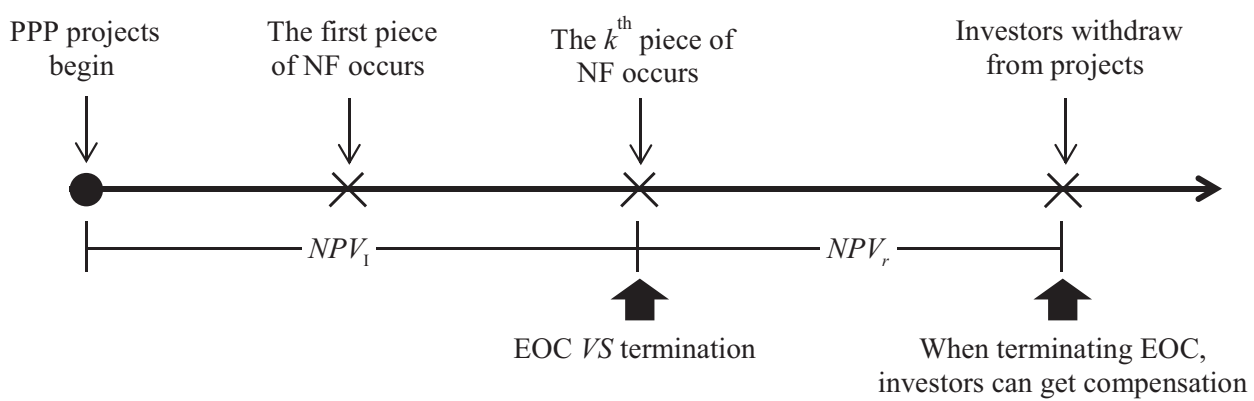

Figure 1. Time series of investors' EOC in PPP projects

from escalation reach a certain point, they will terminate PPP projects and transfer them to governments. Thus, in an escalation scenario for PPP projects, investors own the right to abandon projects once the project value with option is negative. At the point of the termination, the losses are investors' threshold for EOC, being the largest losses that investors can sustain.

With continuous NF, regardless of whether to continue EOC, investors can obtain the project value from the first stage, expressed as $N P V_{\mathrm{I}}$ (Figure 1). When investors choose to abandon EOC, they may obtain some compensation from governments or the residual asset value (expressed by $K$ ) to recoup losses but will relinquish the net present value of the project earnings during the remaining concession period (denoted by $N P V_{r}$ ). As depicted in Figure 2, $V_{E O C}$ is the value with the abandonment option of PPP projects with EOC and $V_{\text {low }}$ represents the termination threshold for investors' EOC. The initial PPP project value with option from the beginning $V_{E O C}$ will jump upward to $V_{E O C}^{+}$with probability $p$ or downward to $V_{E O C}^{-}$with probability $1-p$, where $V_{E O C}^{-}<V_{E O C}<V_{E O C}^{+}$ and $0 \leq p \leq 1$.

Suppose that the government compensation for early termination initiated by investors is $P_{a t}$, the net present value of which is $K$, as shown in Figure 3. In the traditional real option method, the execution condition of a put option is $S-X \leq 0$, which indicates that only when the asset value $(S)$ is no more than the strike price $(X)$ will investors abandon the project. Differently, in the EOC scenario, a certain degree of losses is allowable and investors' termination condition is $V_{\text {low }}<0$, i.e., only when the total net present value $\left(N P V_{\mathrm{I}}+N P V_{r}\right)$ is less than the strike price $(K)$ by a certain extent, i.e., $N P V_{\mathrm{I}}+N P V_{r}-K \leq V_{\text {low }}$, will investors cease EOC in PPP projects, signifying that the execution interval of options is smaller with the reduction interval being exactly the absolute value of $\left|V_{\text {low }}\right|$.

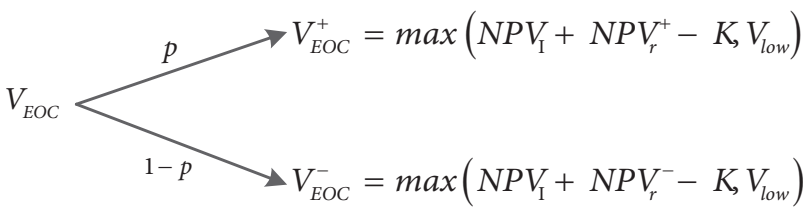

Figure 2. Option model of EOC in PPP projects

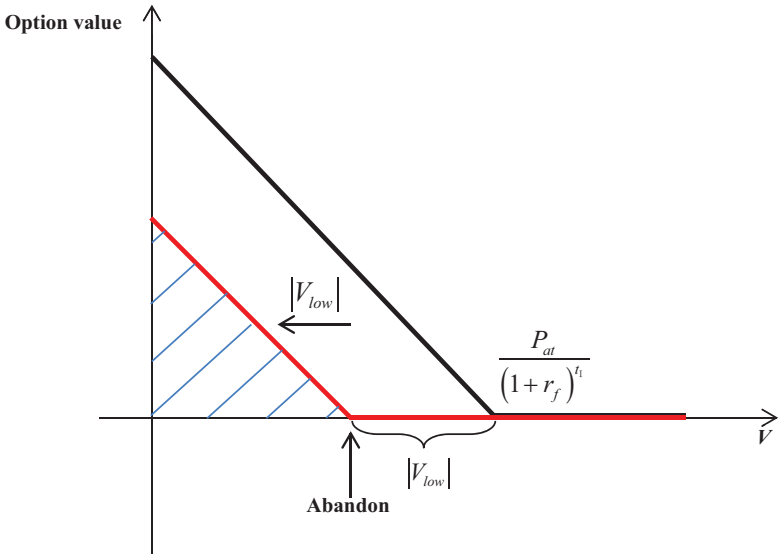

Figure 3. Payoff function for EOC at maturity in PPP projects

\subsection{Determination of threshold for EOC in PPP projects}

Suppose that investors have initially invested partial funds in a PPP project at $t_{0}$, and their initial generative cognition regarding this project is $S_{0}$. Due to uncertainties and risks, investors may continuously receive NF denoted by $k(k=1,2, \ldots)$ in the process of the project, such as severe cost overruns, significant schedule delays or policy changes, indicating that this project is likely to fail. If investors' generative cognition exceeds their dissonant cognition, they will continue to invest in the PPP project, so EOC will persist; in contrast, EOC will be terminated (Festinger, 1962; Kiesler, 1971), as shown in Figure 4.

Based on the belief-adjustment model of human information processing (Hogarth \& Einhorn, 1992), investors usually adopt a stepwise reaction model to process each piece of NF in PPP projects. As depicted in Figure 5, $S_{\mathrm{k}}$ is the degree to which investors adjust their beliefs in terms of impression or attitude after evaluating the $k$ pieces of NF, and $0 \leq S_{k} \leq 1 . S_{k-1}$ is the investors' generative cognition with respect to the $k^{\text {th }}$ piece of NF. $a_{k}$ represents the evidentiary weight of the $k^{\text {th }}$ piece of NF, and $0 \leq a_{k} \leq 1$; the greater $a_{k}$ is, the stronger the evidentiary weight. $\varphi_{k}$ is investors' acceptance degree of the $k^{\text {th }}$ piece of NF and $0 \leq \varphi_{k} \leq 1 . S\left(a_{k}\right)$ represents the subjective evaluation of $a_{k}$, i.e., the dissonant cognition of investors. 


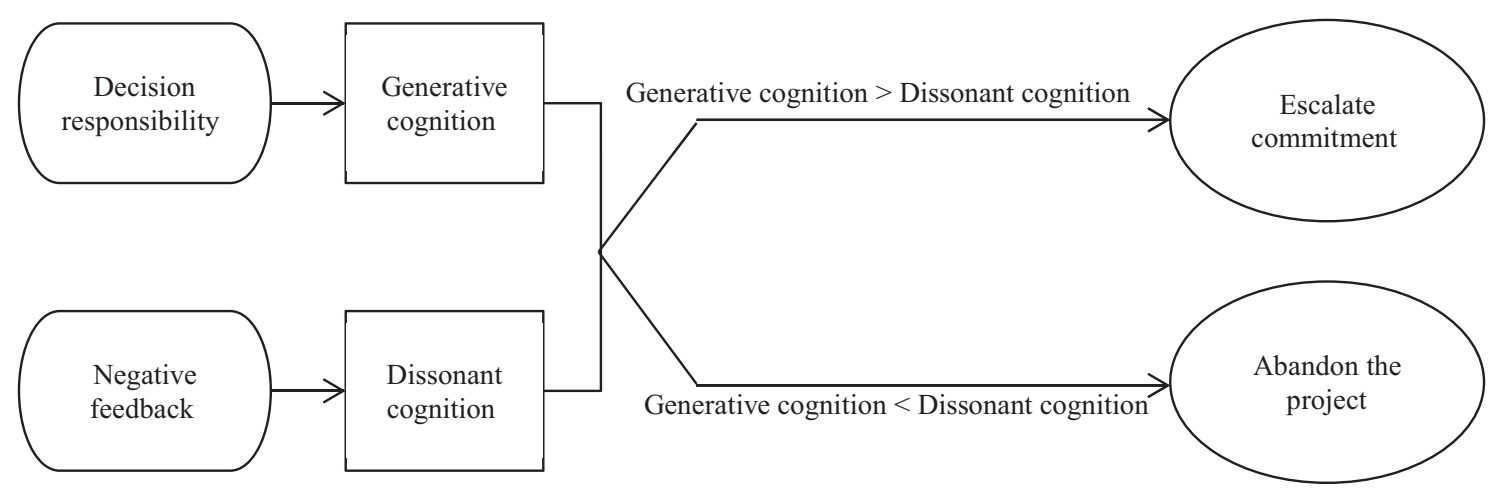

Figure 4. Relationship between generative cognition, dissonant cognition and EOC

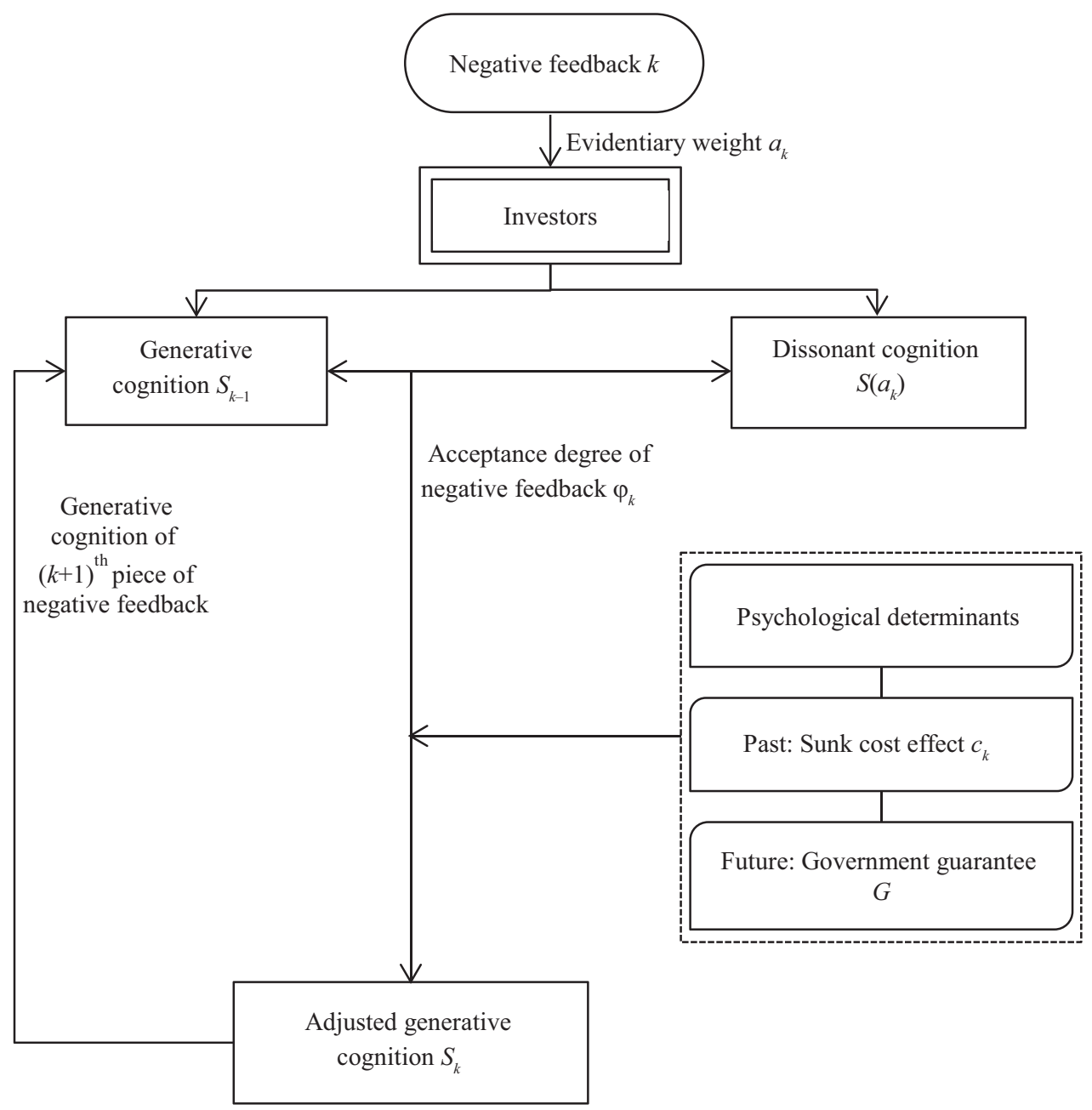

Figure 5. Belief-adjustment model process of EOC

Generally, $S\left(a_{k}\right)$ varies with different attitudes toward risks, background knowledge and the environment and improves with the increased evidentiary weight $a_{k}$ (Tang \& Liu, 2008). Facing ongoing NF, investors' generative cognition regarding the project will decrease gradually as follows (Hogarth \& Einhorn, 1992):

$$
S_{k}=S_{k-1}-\varphi_{k} \cdot S_{k-1} \cdot S\left(a_{k}\right) \text {. }
$$

Starting with the initial generative cognition $S_{0}$, each piece of NF is processed successively. Upon receiving the $k^{\text {th }}$ piece of NF, the generative cognition of this project will fall from $S_{0}$ to $S_{k-1}$, i.e., $0 \leq S_{k-1} \leq S_{k} \leq \ldots \leq S_{2} \leq S_{1} \leq S_{0} \leq 1$. Assume that when investors receive $k_{0}$ piece of NF, the critical condition for terminating EOC is just met, that is, the generative cognition becomes equal to the dissonant cognition, as follows: 


$$
S_{k_{0}-1}=S\left(a_{k_{0}}\right) \text {. }
$$

Therefore, considering the conditions laid out above, the boundary condition for EOC is:

$$
\begin{aligned}
S\left(a_{k_{0}}\right)=S_{k_{0}-1} & =\left[1-\varphi_{k_{0}-1} \cdot S\left(a_{k_{0}-1}\right)\right] \cdot S_{k_{0}-2} \\
& =\ldots \\
& =S_{0} \cdot\left[1-\varphi_{1} \cdot S\left(a_{1}\right)\right] \cdot\left[1-\varphi_{2} \cdot S\left(a_{2}\right)\right] \cdot \ldots \\
& {\left[1-\varphi_{k_{0}-1} \cdot S\left(a_{k_{0}-1}\right)\right] . }
\end{aligned}
$$

As stated above, $a_{k}$ is the evidentiary weight of the $k^{\text {th }}$ piece of NF. If $k=0, a_{k}=0$. In PPP projects, when $k$ is fewer initially, $a_{k}$ is also low, but as increasing amounts of NF emerge, the probability of project failure increases. That is, the evidentiary weight $\left(a_{k}\right)$ is gradually stronger. When $k$ is relatively small, the growth rate of $a_{k}$ is slow; with the increased $k, a_{k}$ improves rapidly. Thus, $a_{k}$ is a monotone incremental function of $k$, and the growth rate of $a_{k}$ is accelerating, which can be expressed as follows:

$$
a_{k}=m_{1} k^{2},
$$

where the coefficient $m_{1}>0$.

The acceptance degree of NF by investors $\left(\varphi_{k}\right)$ is negatively related to the willingness to escalate $\left(w_{k}\right)$. The stronger $w_{k}$ is, the lower $\varphi_{k}$, which can be expressed as follows:

$$
\varphi_{k}=n_{1} w_{k}+l_{1},
$$

where $0 \leq w_{k} \leq 1$ and the coefficient $n_{1}<0$. When $w_{k}$ is extremely small, for instance $w_{k}=0, \varphi_{k}$ is the greatest, i.e., $\varphi_{k_{\max }}=l_{1}$, and thereby $0 \leq l_{1} \leq 1$. $w_{k}$ is affected by many determinants, such as risk preferences (Jani, 2008; Wong, 2005) and self-esteem level (Schaumberg \& Wiltermuth, 2014) etc. As these subjective psychological characteristics of private investors are typically stable, mainly affecting their dissonant cognition (see below for details), the analysis of $w_{k}$ only addresses objective factors. With the escalation decision point as the dividing point, the determinants consist of three categories, including the past sunk cost level $c_{k}$ (Chung \& Cheng, 2018; Rutten et al., 2014; Staw \& Ross, 1987; Westfall et al., 2012), the current evidentiary weight $a_{k}$ and the future government guarantee degree $G$ (Wang \& Liu, 2015; Wang et al., 2018). Specifically, representing the effect of past factors on decision-making, the value of $c_{k}$ is equal to the ratio of all sunk cost utility to the expected full input utility, and $c_{k}>0$; the value of $G$ equals the absolute value of the ratio of government guarantees to the actual profits and $G \in[0,1]$.

According to the literature review, investors usually escalate their commitment in response to sunk costs. Initially, when the sunk cost level $\left(c_{k}\right)$ of the PPP project is low, investors' willingness to escalate $\left(w_{k}\right)$ is relatively strong. With the increased $c_{k}$, $w_{k}$ gradually declines, but the rate of the latter reduction is slower. However, when $c_{k}$ increases to a certain extent and investors clearly per- ceive that PPP projects are likely to fail, their willingness to escalate $\left(w_{k}\right)$ rapidly decreases. Thus, the monotonic decreasing relationship between $w_{k}$ and $c_{k}$ can be described by a quadratic function with an inverse $u$-shape. With regard to the evidentiary weight $a_{k}$, a stronger $a_{k}$ means greater credibility of the project failure, thereby leading to a weaker $w_{k}$ to continue projects. That is, $w_{k}$ is negatively correlated with $a_{k}$. Moreover, as higher guarantees help reduce project risks and losses, $w_{k}$ also improves with $G$ in the future. Considering the three determinants are classified based on the time point of re-decision-making, these determinants are independent and do not interfere with one another. As a result, the relationship among $w_{k}$ and $c_{k}, a_{k}$ and $G$ can be expressed as follows:

$$
w_{k}=\left(m_{2} c_{k}^{2}+l_{2}\right)+\left(n_{2} a_{k}+l_{3}\right)+\left(n_{3} G+l_{4}\right),
$$

where the coefficient $m_{2}<0, l_{2} \in[0,1], n_{2}<0, l_{3} \in[0,1]$, $n_{3}>0$ and $l_{4} \in[0,1]$.

According to Eqs. (4) to (6), the acceptance degree $\varphi_{k}$ is derived as follows:

$$
\varphi_{k}=\zeta_{1} c_{k}^{2}+\zeta_{2} k^{2}-\zeta_{3} G+\zeta_{4},
$$

where: $\zeta_{1}=m_{2} n_{1}, \zeta_{2}=m_{1} n_{1} n_{2}, \zeta_{3}=-n_{1} n_{3}$, $\zeta_{4}=n_{1}\left(l_{2}+l_{3}+l_{4}\right)+l_{1}$ and $\zeta_{1}, \zeta_{2}, \zeta_{3}>0$.

As dissonant cognition $S\left(a_{k}\right)$ improves with the increased evidentiary weight $a_{k}$ and drawing on the value function of cumulative prospect theory focusing on the psychological determinants (Kahneman \& Tversky, 1979), the dissonant cognition $S\left(a_{k}\right)$ can be expressed as follows:

$$
S\left(a_{k}\right)=\lambda\left(a_{k}\right)^{\beta}=\lambda\left(m_{1} k^{2}\right)^{\beta},
$$

where: $\beta$ is the risk attitude coefficient of investors $(0 \leq \beta \leq 1)$ and $\lambda$ is the risk aversion coefficient $(\lambda>1)$.

According to Eqs. (7) and (8), investors' generative cognition for the $k_{0}^{\text {th }}$ piece of NF can be inferred as follows:

$S_{k_{0}-1}=S_{0} \prod_{i=1}^{k_{0}-1}\left[1-\left(\zeta_{1} c_{i}^{2}+\zeta_{2} i^{2}-\zeta_{3} G+\zeta_{4}\right) \cdot \lambda\left(m_{1} i^{2}\right)^{\beta}\right]$.

Then, the critical condition for terminating EOC by investors in the PPP project is:

$$
S_{0} \prod_{i=1}^{k_{0}-1}\left[1-\left(\zeta_{1} c_{i}^{2}+\zeta_{2} i^{2}-\zeta_{3} G+\zeta_{4}\right) \cdot \lambda\left(m_{1} i^{2}\right)^{\beta}\right]=\lambda\left(m_{1} k_{0}^{2}\right)^{\beta} .
$$

Given that each piece of NF is processed successively based on the initial generative cognition $S_{0}$, there always exists a minimum $k_{0}\left(k_{0} \geq 0\right)$ that satisfies Eq. (10), which is the greatest amount of NF that investors can tolerate. When the actual amount of NF received $k$ is not more than $k_{0}\left(k<k_{0}\right)$, investors' generative cognition exceeds the dissonant cognition, and then they will escalate their commitment to the PPP project. With the continuous NF received, the generative cognition of the project gradually decreases. Until $k_{0}$ pieces of NF occur, generative cognition no longer exceeds dissonant cognition, and the investors will terminate the project. 
When receiving the $k_{0}^{\text {th }}$ piece of NF, the generative cognition is $S_{\text {min }}$, as shown in Eq. (11), which is the lowest generative cognition accepted by the investors with regard to the PPP project.

$S_{\min }=S_{k_{0}-1}=S_{0} \prod_{i=1}^{k_{0}-1}\left[1-\left(\zeta_{1} c_{i}^{2}+\zeta_{2} i^{2}-\zeta_{3} G+\zeta_{4}\right) \cdot \lambda\left(m_{1} i^{2}\right)^{\beta}\right]<S_{0}$.

In the EOC scenario of PPP projects, the greatest degree of losses $\left(\varepsilon_{0}\right)$ that investors can sustain is:

$\varepsilon_{0}=\frac{S_{\min }-S_{0}}{S_{0}}=\prod_{i=1}^{k_{0}-1}\left[1-\left(\zeta_{1} c_{i}^{2}+\zeta_{2} i^{2}-\zeta_{3} G+\zeta_{4}\right) \cdot \lambda\left(m_{1} i^{2}\right)^{\beta}\right]-1$,

where $-1 \leq \varepsilon_{0} \leq 0$. The negative symbol represents losses, and the absolute value represents the greatest acceptable degree of investors' losses.

Assume that the return on investment for the PPP project is $\stackrel{\circ}{R}=f(t)$. This implies that $\stackrel{\circ}{R}$ is a function of time $t$ (typically, $R$ increases with $t$ and vice versa) (Liu et al., 2017). Generally, the longer the operation period $(t)$, the higher the actual cash flows and then the higher $R$ will be. In such a case, the termination threshold $\left(V_{\text {low }}\right)$ for the escalation behavior is:

$$
V_{\text {low }}=I \cdot \stackrel{\circ}{R} \cdot \varepsilon_{0}=I \cdot f(t) \cdot\left\{\prod_{i=1}^{k_{0}-1}\left[1-\left(\zeta_{1} c_{i}^{2}+\zeta_{2} i^{2}-\zeta_{3} G+\zeta_{4}\right) \cdot \lambda\left(m_{1} i^{2}\right)^{\beta}\right]-1\right\} \text {, }
$$

where: $I$ is the total investment of the project.

To sum up, the definitions of these relevant parameters are presented in Table 1.

Investors' dissonant cognition $S\left(a_{k}\right)=\lambda\left(a_{k}\right)^{\beta}=$ $\lambda\left(m_{1} k^{2}\right)^{\beta}$ improves with the increased evidentiary weight $a_{k}$ and further with the increased amount of NF $(k)$ in PPP projects. If $\lambda\left(m_{1}\right)^{\beta}=1$ with $k=1$, the evidentiary weight of NF is strong enough to cause investors' minimum dissonant cognition to reach the highest intensity of one. Once the investors receive NF, the dissonant cognition becomes intense, and they will definitely abandon the project. In this scenario, the investors will not escalate their commitment. On the contrary, if $\lambda\left(m_{1} k^{2}\right)^{\beta}$ is extremely small whatever $k$ is, for instance $\lambda\left(m_{1} k^{2}\right)^{\beta}=0, a_{k}$ is too weak to result in dissonant cognition of private investors, and they will accordingly not escalate their commitment (Tang \& Liu, 2008). As such, when escalation behavior occurs, the investors' dissonant cognition on the project must satisfy the condition $0<\lambda\left(m_{1} k^{2}\right)^{\beta}<1$.

For private investors, the greatest tolerable amount of NF $\left(k_{0}\right)$ satisfies the condition $S_{0} \prod_{i=1}^{k_{0}-1}\left[1-\left(\zeta_{1} c_{i}^{2}+\zeta_{2} i^{2}-\zeta_{3} G+\zeta_{4}\right) \cdot \lambda\left(m_{1} i^{2}\right)^{\beta}\right]=\lambda\left(m_{1} k_{0}^{2}\right)^{\beta}$. In this sense, $k_{0}$ is positively related to the investors' initial generative cognition $\left(S_{0}\right)$. The higher $S_{0}$ is, the greater $k_{0}$ will be. If initial generative cognition $\left(S_{0}\right)$ becomes sufficiently low that it equals the weakest dissonant cognition $\lambda\left(m_{1}\right)^{\beta}$ when $k=1$, i.e. $S_{0}=\lambda\left(m_{1}\right)^{\beta}$, the first piece of NF presented will exceed investors' largest tolerable quantity. In this case, the investors will not escalate their commitment and will abandon the project upon receipt of NF. When such initial generative cognition $\left(S_{0}\right)$ is greater than the weakest dissonant cognition generated with $k=1$, i.e. $S_{0}>\lambda\left(m_{1}\right)^{\beta}$, then $k_{0} \geq 2$. In other words, the investors will persist in PPP projects upon receiving, at least, the first piece of NF, thereby engaging in escalation behavior. Based on $k_{0}$, the threshold is determined, i.e. $V_{\text {low }}=I \stackrel{\circ}{R} \varepsilon_{0}=I \cdot f(t) \cdot\left\{\prod_{i=1}^{k_{0}-1}\left[1-\left(\zeta_{1} c_{i}^{2}+\zeta_{2} i^{2}-\zeta_{3} G+\zeta_{4}\right) \cdot \lambda\left(m_{1} i^{2}\right)^{\beta}\right]-1\right\}$. In summary, the threshold is influenced by various factors as described below.

(1) The absolute value of the threshold for investors' EOC $\left(\left|V_{\text {low }}\right|\right)$ is positively related to the total investment $(I)$. The larger $I$ is, particularly the greater the sunk cost, the more willing an investor is to engage in EOC. The sunk cost effect is present in the escalation scenario (Heath, 1995; Karlsson et al., 2005; Ku et al., 2005). To avoid acknowledging that these resources have been wasted, investors persist in their investments. As sunk costs increase, the greatest losses that investors can sustain become increasingly severe, and hence $\left|V_{\text {low }}\right|$ will increase.

(2) The threshold range $\left|V_{\text {low }}\right|$ expands as the return on investment $(R)$ in the PPP project increases and is further positively correlated with the period $t$ because $\stackrel{0}{R}=f(t)$ and $\stackrel{0}{R}$ is an increasing function of $t$. The longer $t$, the higher $R$ should be. According to expectancy theory (Vroom, 1964), investors will invest even more resources based on their targeted return on investment, and then $\left|V_{\text {low }}\right|$ increases, leading to increasingly significant escalation behavior.

(3) Contrary to intuition, the government guarantee level $G$ will not reduce investors' losses in PPP projects. As depicted in Eqs. (7) and (9), when $G$ declines and other parameters remain unchanged, the value of $\left[1-\left(\zeta_{1} c_{i}^{2}+\zeta_{2} i^{2}-\zeta_{3} G+\zeta_{4}\right) \cdot \lambda\left(m_{1} i^{2}\right)^{\beta}\right] \quad\left(i=1,2, \ldots, k_{0}\right)$ will decline. A relatively small $k_{0}$ will result in their generative cognition being less than their dissonant cognition, and the escalation will be terminated quickly, indicating that $\left|V_{\text {low }}\right|$ also decreases. In other words, an increased $G$ will indirectly increase $\left|V_{\text {low }}\right|$ in PPP projects or will at least not decrease $\left|V_{\text {low }}\right|$.

(4) When other parameters are fixed, an increase in generative cognition $\left(S_{0}\right)$ at the initial time can prompt investors to adopt a higher level of escalation behavior, resulting in a larger $\left|V_{\text {low }}\right|$. A higher $S_{0}$ implies that stronger faith has been invested in the PPP project. Since information processing usually conforms to a stepwise reaction model, this procedure slows down given a higher $S_{0}$. That is, investors will process more NF, thus improving $\left|V_{\text {low }}\right|$.

(5) The value $\left|V_{\text {low }}\right|$ is also directedly determined by investors' behavioral preferences, including $\lambda, \beta, m_{o}$ $(o=1,2), n_{p}(p=1,2,3)$ and $l_{q}(q=1,2,3,4)$. According to the critical condition shown in Eq. (10), an increased risk aversion coefficient $\lambda$ or risk attitude coefficient $\beta$ represents increased sensitivity to losses and risks, signify- 
Table 1. The definitions of variables related to the threshold for investors' EOC

\begin{tabular}{|c|c|c|}
\hline Symbols & Range of values & Definitions \\
\hline$t_{0}$ & $t_{0}>0$ & Initial time of investment by investors \\
\hline$t$ & $t>0$ & The time of PPP projects after investment \\
\hline$k$ & $k>0$ and being a positive integer & The amount of NF \\
\hline$S_{0}$ & $0 \leq S_{0} \leq 1$ & Initial generative cognition of private investors \\
\hline$S_{k-1}$ & $0 \leq S_{k-1} \leq S_{k} \leq 1$ & Investors' generative cognition regarding the $k^{\text {th }}$ piece of NF \\
\hline$a_{k}$ & $0 \leq a_{k} \leq 1$ & The evidentiary weight of the $k^{\text {th }}$ piece of NF \\
\hline$\varphi_{k}$ & $0 \leq \varphi_{k} \leq 1$ & The acceptance degree of the $k^{\text {th }}$ piece of NF \\
\hline$S\left(a_{k}\right)$ & $0 \leq S\left(a_{k}\right) \leq 1$ & The dissonant cognition of investors with the $k^{\text {th }}$ piece of NF \\
\hline$w_{k}$ & $0 \leq w_{k} \leq 1$ & The willingness to escalate by investors \\
\hline$c_{k}$ & $c_{k}>0$ & Sunk cost level \\
\hline$G$ & $0 \leq G \leq 1$ & The government guarantee degree \\
\hline$\beta$ & $0 \leq \beta \leq 1$ & The risk attitude coefficient of investors \\
\hline$\lambda$ & $\lambda>1$ & The risk aversion coefficient \\
\hline$n_{1}$ & $n_{1}<0$ & The linear coefficient between $\varphi_{k}$ and $w_{k}$ \\
\hline$n_{2}$ & $n_{2}<0$ & The linear coefficient between $w_{k}$ and $a_{k}$ \\
\hline$n_{3}$ & $n_{3}>0$ & The linear coefficient between $w_{k}$ and $G$ \\
\hline$m_{1}$ & $m_{1}>0$ & The coefficient of quadratic function between $a_{k}$ and $k$ \\
\hline$m_{2}$ & $m_{2}<0$ & The coefficient of quadratic function between $w_{k}$ and $c_{k}$ \\
\hline$l_{1}$ & $0 \leq l_{1} \leq 1$ & The intercept of function between $\varphi_{k}$ and $w_{k}$ \\
\hline$l_{2}$ & $0 \leq l_{2} \leq 1$ & The intercept of function between $w_{k}$ and $c_{k}$ \\
\hline$l_{3}$ & $0 \leq l_{3} \leq 1$ & The intercept of function between $w_{k}$ and $a_{k}$ \\
\hline$l_{4}$ & $0 \leq l_{4} \leq 1$ & The intercept of function between $w_{k}$ and $G$ \\
\hline$\zeta_{1}$ & $\zeta_{1}=n_{1} m_{2}>0$ & The coefficient of quadratic function between $\varphi_{k}$ and $c_{k}$ \\
\hline$\zeta_{2}$ & $\zeta_{2}=n_{1} n_{2} m_{1}>0$ & The coefficient of quadratic function between $\varphi_{k}$ and $k$ \\
\hline$\zeta_{3}$ & $\zeta_{3}=-n_{1} n_{3}>0$ & The linear coefficient between $\varphi_{k}$ and $G$ \\
\hline$\zeta_{4}$ & $n_{1}\left(l_{2}+l_{3}+l_{4}\right)+l_{1}=\zeta_{4}$ & The intercept of function between $\varphi_{k}$ and $c_{k}, k$ and $G$ \\
\hline$\varepsilon_{0}$ & $-1 \leq \varepsilon_{0} \leq 0$ & The greatest degree of losses \\
\hline$\stackrel{\circ}{R} / R$ & $\stackrel{\circ}{R}=f(t)$ & The return on investment for the PPP project \\
\hline$I$ & $I>0$ & The total investment of the project \\
\hline$V_{\text {low }}$ & $V_{\text {low }}=I \cdot \stackrel{\circ}{R} \cdot \varepsilon_{0}<0$ & Termination threshold for investors' EOC \\
\hline
\end{tabular}

ing that the investors' dissonant cognition $\lambda\left(m_{1} k^{2}\right)^{\beta}$ will increase and that $\left[1-\left(\zeta_{1} c_{i}^{2}+\zeta_{2} i^{2}-\zeta_{3} G+\zeta_{4}\right) \cdot \lambda\left(m_{1} i^{2}\right)^{\beta}\right]$ $\left(i=1,2, \ldots, k_{0}\right)$ will decrease. Similarly, when investors receive fewer pieces of NF, their generative cognition will be less than their dissonant cognition, and conversely, the escalation will be terminated quickly. However, if the coefficients $\zeta_{1}, \zeta_{2}$ and $\zeta_{4}$ increase or the coefficient $\zeta_{3}$ declines, their dissonant cognition $\lambda\left(m_{1} k^{2}\right)^{\beta}$ will not be influenced, but $\left[1-\left(\zeta_{1} c_{i}^{2}+\zeta_{2} i^{2}-\zeta_{3} G+\zeta_{4}\right) \cdot \lambda\left(m_{1} i^{2}\right)^{\beta}\right]$ will decrease. Based on the stepwise reaction method, the equilibrium between investors' generative and dissonant cognition will be reached upon receiving fewer pieces of NF in this case. Thus, the escalation behavior will be terminated more rapidly, and thereby $\left|V_{\text {low }}\right|$ will be reduced. 


\subsection{Project value with option in the EOC scenario}

In PPP projects with investors' EOC, early termination is inevitable. In such a scenario, investors have the right to require governments to take over the project in advance as initially agreed but with no obligations. It is possible that early termination will occur at any given time during the franchise period, and hence, the abandonment right that the investors hold is an American put option. As displayed in Figure 6, during the concession period (denoted by $T$ ), when the cumulative actual cash flows (denoted by $C F_{i}^{\alpha}$ ) are lower than the predicted cash flows (i.e., $C F_{i}$ ) by a certain extent as expressed in Eq. (14), the investors will terminate such escalation behavior and transfer the project to governments.

$$
\sum_{i=t_{0}}^{t_{\mathrm{I}}} C F_{i}^{\alpha} \leq(1-\chi) \times \sum_{i=t_{0}}^{t_{\mathrm{I}}} C F_{i} .
$$

where: $\chi$ is the difference between the cumulative actual and projected cash flows and $t_{\mathrm{I}}$ is the time at which the difference between the actual and predicted cash flows reaches $\chi$. At this point, the net present value of the project obtained by the investor $\left(N P V_{\mathrm{I}}\right)$ and the net present value of the project during its remaining concession pe$\operatorname{riod}\left(N P V_{r}\right)$ are, respectively:

$$
\begin{aligned}
& N P V_{\mathrm{I}}=\sum_{i=t_{0}}^{t_{\mathrm{I}}} \frac{C F_{i}^{\alpha}}{\left(1+r_{i}\right)^{i}} ; \\
& N P V_{r}=\sum_{i=t_{\mathrm{I}+1}}^{T} \frac{C F_{i}^{\alpha}}{\left(1+r_{i}\right)^{i}},
\end{aligned}
$$

where: $r_{i}$ is the discount rate.

With the abandonment option of early termination, the project value to the investors is $N P V_{\text {opt }}=\sum_{i=t_{0}}^{t_{\mathrm{I}}} \frac{C F_{i}^{\alpha}}{\left(1+r_{i}\right)^{i}}+\frac{P_{a t}}{\left(1+r_{f}\right)^{t_{\mathrm{I}}}}$, where $r_{f}$ is the riskfree rate. If there is no flexibility in the policymaker layer,

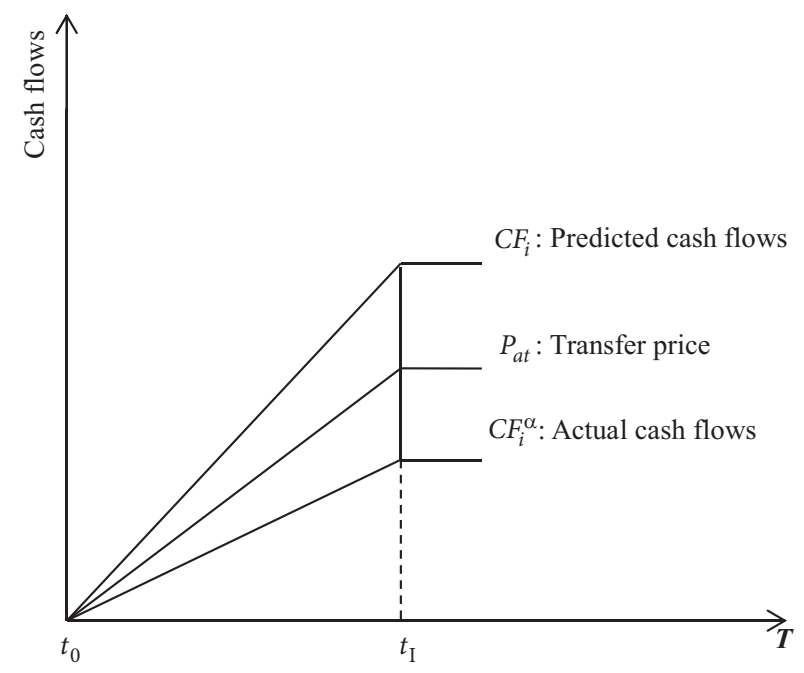

Figure 6. Cash flows for early termination in PPP projects with EOC investors will not have put option and will have to operate the project at a loss, and the value of investors without options is $N P V=\sum_{i=t_{0}}^{T} \frac{C F_{i}^{\alpha}}{\left(1+r_{i}\right)^{i}}$. When comparing the two opposite scenarios with and without flexibility, the difference in value for investors is the option value with early termination as follows:

$$
V_{R O}=N P V_{o p t}-N P V=K-N P V_{r}=\frac{P_{a t}}{\left(1+r_{f}\right)^{t_{1}}}-\sum_{i=t_{I+1}}^{T} \frac{C F_{i}^{\alpha}}{\left(1+r_{i}\right)^{i}} .
$$

From the perspective of options, the option value is not less than zero, i.e., the termination price for investors must be sufficient to compensate for their residual cash flows during the remaining concession period from time $t_{\mathrm{I}+1}$ to time $T$, as follows:

$$
V_{R O}=\frac{P_{a t}}{\left(1+r_{f}\right)^{j}}-\sum_{i=t_{\mathrm{I}+1}}^{T} \frac{C F_{i}^{\alpha}}{\left(1+r_{i}\right)^{i}} \geq 0 .
$$

On the other hand, government guarantees are typically deemed essential to formulate appropriate incentive mechanisms in PPP projects (Buyukyoran \& Gundes, 2018; Liu et al., 2014; Wang et al., 2018). This requires the termination price to yield a proper return on investment to investors as the following prerequisites describe:

$$
N P V_{\text {opt }}=\sum_{i=t_{0}}^{t_{\mathrm{I}}} \frac{C F_{i}^{\alpha}}{\left(1+r_{i}\right)^{i}}+\frac{P_{a t}}{\left(1+r_{f}\right)^{t_{\mathrm{I}}}} \geq I \stackrel{\circ}{R} .
$$

Although governments shoulder social responsibility, the economic benefits of projects reflect, to some extent, project success and hence need to be ensured. That is, the net present value for governments after an advance purchase is greater than zero as follows:

$$
N P V_{g}=\sum_{i=t_{\mathrm{I}+1}}^{T_{C}} \frac{C F_{i}^{\alpha}}{\left(1+r_{i}\right)^{i}}-\frac{P_{a t}}{\left(1+r_{f}\right)^{j}} \geq 0,
$$

where: $N P V_{g}$ represents the project value to governments when purchasing a project in advance and $T_{C}$ is the life cycle of the project. Thus, considering both the investor and government conditions laid out in the above equations, the boundary conditions for the termination price in PPP projects can be inferred as follows:

$$
\begin{aligned}
& \left(1+r_{f}\right)^{t_{\mathrm{I}}} \times \operatorname{Max}\left(\sum_{i=t_{\mathrm{I}+1}}^{T} \frac{C F_{i}^{\alpha}}{\left(1+r_{i}\right)^{i}}, I \stackrel{\mathrm{o}}{R}-\sum_{i=t_{0}}^{t_{\mathrm{I}}} \frac{C F_{i}^{\alpha}}{\left(1+r_{i}\right)^{i}}\right) \leq \\
& P_{a t} \leq\left(1+r_{f}\right)^{t_{\mathrm{I}}} \times \sum_{i=t_{\mathrm{I}+1}}^{T_{\mathrm{C}}} \frac{C F_{i}^{\alpha}}{\left(1+r_{i}\right)^{i}} .
\end{aligned}
$$

In reality, private investors typically terminate EOC once the actual cash flows of PPP projects are small enough to satisfy the condition $\sum_{i=t_{0}}^{t_{\mathrm{I}}} C F_{i}^{\alpha}=(1-\chi) \times \sum_{i=t_{0}}^{t_{\mathrm{I}}} C F_{i}$. In this scenario, the range of $P_{a t}$ is: 


$$
\begin{aligned}
& \left(1+r_{f}\right)^{t_{1}} \times \operatorname{Max}\left((1-\chi) \times \sum_{i=t_{I+1}}^{T} \frac{C F_{i}}{\left(1+r_{i}\right)^{i}}, I R-(1-\chi) \times \sum_{i=t_{0}}^{t_{1}} \frac{C F_{i}}{\left(1+r_{i}\right)^{i}}\right) \leq \\
& P_{a t} \leq\left(1+r_{f}\right)^{t_{1}} \times(1-\chi) \times \sum_{i=t_{I+1}}^{T_{C}} \frac{C F_{i}}{\left(1+r_{i}\right)^{i}} .
\end{aligned}
$$

The derivation of early termination prices up front serves as a valuable benchmark and a good starting point for both governments and investors during negotiations. Nonetheless, the final compensation (denoted by $P_{a t}^{\alpha}$ ) agreed upon as specified in the concession agreement of early termination in PPP projects with investor' EOC is also dependent on the bargaining power of each party. In this scenario, the actual option value $\left(V_{R O}^{\alpha}\right)$ that the investors own after negotiations is:

$$
V_{R O}^{\alpha}=K-N P V_{r}=\frac{P_{a t}^{\alpha}}{\left(1+r_{f}\right)^{t_{\mathrm{I}}}}-\sum_{i=t_{\mathrm{I}+1}}^{T} \frac{C F_{i}^{\alpha}}{\left(1+r_{i}\right)^{i}} .
$$

Consequently, the value of a PPP project $\left(V_{E O C}\right)$ with option in the EOC scenario is:

$$
V_{E O C}=N P V_{\mathrm{I}}+N P V_{r}+V_{R O}^{\alpha}=\sum_{i=t_{0}}^{t_{\mathrm{I}}} \frac{C F_{i}^{\alpha}}{\left(1+r_{i}\right)^{i}}+\frac{P_{a t}^{\alpha}}{\left(1+r_{f}\right)^{t_{\mathrm{I}}}} \text {. }
$$

The above parameters are summarized in Table 2. Briefly, when $V_{\text {low }}<V_{E O C}$, investors will continue to escalate their commitment to PPP projects, whereas when $V_{E O C} \leq V_{\text {low }}$, the losses have increased beyond the range that investors will endure, and they will cease the escalation and withdraw from the project.

\section{Numerical example}

To illustrate the application of the approach and facilitate understanding, this section demonstrates the models using a numerical example. The variables mentioned above can be divided into two categories: project- and investor-related variables. Project-related variables include the variables to be determined by governments and investors in advance after negotiations in PPP projects such as the expected return on investment $(\stackrel{\circ}{R})$. The total collective amount of investment made by the two sides is used to derive the investment level of PPP projects $(I)$. In terms of investor-related variables, the behavioral preferences of private investors are relatively stable traits and are mostly held constant, but different investors usually have different preferences. Once appropriate investors are selected as partners in PPP projects, techniques can be used to measure their behavioral preferences. Ideally, as an agent to construct and operate PPP projects, investors can comprehend the status of the projects; the evidentiary weight of NF, i.e. the coefficient $m_{1}$ can be derived such as through management platform to analyze the collected information. In addition, attempts can be made to calibrate investors' behavioral preferences $\varphi_{k}$ and $w_{k}$, i.e., the coefficients $m_{2}, n_{p}(p=1,2,3)$ and $l_{q}(q=1,2,3,4)$. The behavioral preferences of private investors can primarily be captured through the past performance of previous

\begin{tabular}{|c|c|}
\hline Symbols & Definitions \\
\hline$C F_{i}$ & The predicted cash flows \\
\hline$C F_{i}^{\alpha}$ & The actual cash flows \\
\hline$\chi$ & $\begin{array}{l}\text { The difference between the cumulative actual and } \\
\text { projected cash flows }\end{array}$ \\
\hline$t_{\mathrm{I}}$ & $\begin{array}{l}\text { The time at which the difference between the } \\
\text { actual and predicted cash flows reaches } \chi\end{array}$ \\
\hline$T$ & The concession period \\
\hline$T_{C}$ & The life cycle of the project \\
\hline$N P V_{\mathrm{I}}$ & $\begin{array}{l}\text { The net present value of the project obtained by } \\
\text { the investor }\end{array}$ \\
\hline$N P V_{r}$ & $\begin{array}{l}\text { The net present value of the project during its } \\
\text { remaining concession period }\end{array}$ \\
\hline$N P V_{o p t}$ & $\begin{array}{l}\text { The project value with expanded option to the } \\
\text { investors }\end{array}$ \\
\hline$N P V$ & The value of investors without options \\
\hline$N P V_{g}$ & $\begin{array}{l}\text { The project value to governments when } \\
\text { purchasing a project in advance }\end{array}$ \\
\hline$r_{i}$ & The discount rate \\
\hline$r_{f}$ & The risk-free rate \\
\hline$P_{a t}$ & $\begin{array}{l}\text { The government compensation for early } \\
\text { termination initiated by investors }\end{array}$ \\
\hline$P_{a t}^{\alpha}$ & $\begin{array}{l}\text { The final early termination compensation agreed } \\
\text { upon as specified in the concession agreement }\end{array}$ \\
\hline K & $\begin{array}{l}\text { The net present value of } P_{a t} \text {, i.e., the strike price of } \\
\text { the put option }\end{array}$ \\
\hline$V_{R O}$ & The option value with early termination \\
\hline$V_{R O}^{\alpha}$ & $\begin{array}{l}\text { The actual option value that the investors own } \\
\text { after negotiations }\end{array}$ \\
\hline$V_{E O C}$ & $\begin{array}{l}\text { The value of a PPP project with option in the } \\
\text { EOC scenario }\end{array}$ \\
\hline
\end{tabular}
PPP projects that they have participated in. Additionally,
Table 2. The definitions of variables related to project value model with investors' EOC

when using similar settings, laboratory experiments can be adopted to test the behavioral preferences of the chosen investors. Moreover, questionnaires or simulations could be designed to collect data if necessary.

Collectively, both project- and investor-related variables can be obtained through a series of records and some other attempts to simulate to present one possible situation. The relevant parameters are assigned as shown in Table 3. Assume that the expected return on investment $(\stackrel{\circ}{R})$ is agreed to be $6 \%$ and the total investment amounts to 10000 (in millions of units of currency dollars, for example), i.e., $R=6 \%$ and $I=10000$. Assume that $m_{1}=0.001, m_{2}=-1, n_{1}=-0.001, n_{2}=-1, n_{3}=0.01$ and $l_{1}=l_{2}=l_{3}=l_{4}=0.01$. The risk attitude coefficient is 0.88 , and the risk-aversion coefficient is 2.25, i.e., $\beta=0.88$ and $\lambda=2.25$ (Tversky \& Kahneman, 1992). In PPP projects, the sunk cost level $c_{k}$, government guarantee degree $G$ and initial generative cognition of investors $S_{0}$ will largely determine the threshold for investors' EOC. Once 
the amount of NF $\left(k_{0}\right)$ that the investors can sustain is known, the threshold ( $\left.V_{\text {low }}\right)$ is determined. Then, the relationships between $V_{\text {low }}$ and $k_{0}$ with $c_{k}$, $G$ and $S_{0}$ will be discussed successively.

Since $c_{k}$ gradually increases as the PPP project progresses, suppose that $c_{k}$ is an incremental arithmetic sequence based on $c_{1}$ upon the first piece of NF (e.g., $\left.c_{1}=0.1\right)$. If the growth rate $\left(c_{k}-c_{k-1}\right)$ is different, then $c_{k}$ is different. First, when the level of government guarantee is fixed (e.g., $G=0.35$ ), the relationship between $k_{0}$ and $c_{k}-c_{k-1}$ and $S_{0}$ is depicted in Figure 7 . The results reveal that $k_{0}$ improves significantly when $S_{0}$ increases, but the decrease in $k_{0}$ following an increase in $c_{k}-c_{k-1}$ is less evident, and $k_{0}$ remains unchanged because $k_{0}$ is a positive integer. The results of the numerical simulation regarding the threshold $V_{\text {low }}$ to $c_{k}-c_{k-1}$ and $S_{0}$ is presented below (Figure 8). The overall trends of $k_{0}$ and $V_{\text {low }}$ appear to follow a similar "step-like" pattern. However, contrary to the results for $k_{0}, V_{\text {low }}$ clearly declines with the increase in $S_{0}$, implying that the investors will delay the termination of EOC.

Table 3. The assigned value of variables

\begin{tabular}{|c|c|c|c|c|}
\hline $\begin{array}{l}\text { Category } \\
\text { of } \\
\text { variables }\end{array}$ & $\begin{array}{l}\text { Basically } \\
\text { assumed } \\
\text { or } \\
\text { scenarios } \\
\text { simulated }\end{array}$ & Variables & $\begin{array}{c}\text { Assigned } \\
\text { value }\end{array}$ & Units \\
\hline \multirow{2}{*}{$\begin{array}{l}\text { Project- } \\
\text { related } \\
\text { variables }\end{array}$} & \multirow{13}{*}{$\begin{array}{l}\text { Basically } \\
\text { assumed }\end{array}$} & $R$ & $6 \%$ & - \\
\hline & & $I$ & 10000 & $\begin{array}{c}\text { Millions of units } \\
\text { of currency } \\
\text { dollars }\end{array}$ \\
\hline \multirow{14}{*}{$\begin{array}{l}\text { Investor- } \\
\text { related } \\
\text { variables }\end{array}$} & & $m_{1}$ & 0.001 & - \\
\hline & & $m_{2}$ & -1 & - \\
\hline & & $n_{1}$ & -0.001 & - \\
\hline & & $n_{2}$ & -1 & - \\
\hline & & $n_{3}$ & 0.01 & - \\
\hline & & $l_{1}$ & 0.01 & - \\
\hline & & $l_{2}$ & 0.01 & - \\
\hline & & $l_{3}$ & 0.01 & - \\
\hline & & $l_{4}$ & 0.01 & - \\
\hline & & $\beta$ & 0.88 & - \\
\hline & & $\lambda$ & 2.25 & - \\
\hline & \multirow{2}{*}{ Scenario 1} & $c_{1}$ & 0.1 & - \\
\hline & & $G$ & 0.35 & - \\
\hline & Scenario 2 & $c_{k}-c_{k-1}$ & 0.05 & - \\
\hline
\end{tabular}

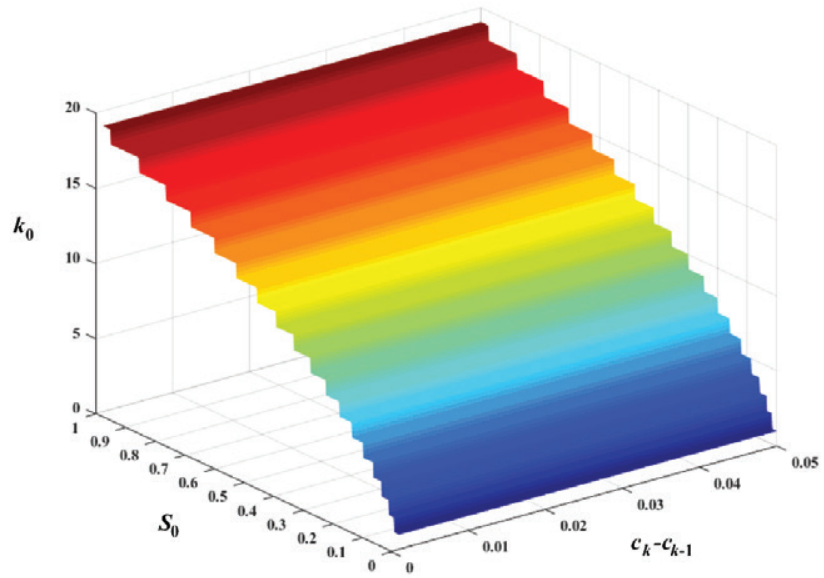

Figure 7. Relationship between $k_{0}, S_{0}$ and $c_{k}-c_{k-1}$

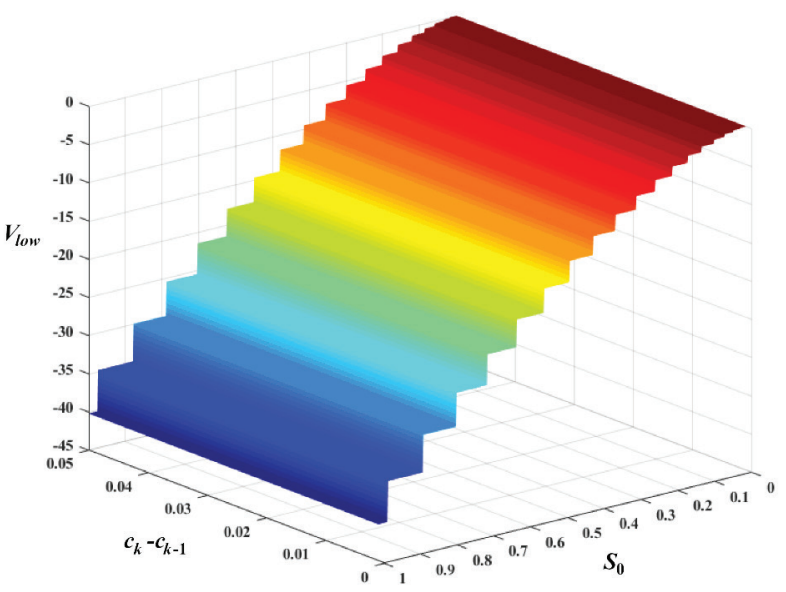

Figure 8. Relationship between $V_{\text {low }}, S_{0}$ and $c_{k}-c_{k-1}$

When the sunk cost level $c_{k}$ of PPP projects is fixed (e.g., $c_{k}-c_{k-1}=0.05$ ), Figure 9 indicates that $k_{0}$ increases as $S_{0}$ increases and will at least not decrease when $G$ increases. When $G$ is unchanged, the effect of $S_{0}$ on $k_{0}$ is clear. By comparison, the influence of $G$ in this scenario is relatively weak. In other words, investors' escalation will be terminated more quickly with a change of $S_{0}$ when both $G$ and $S_{0}$ change to the same degree. Likewise, based on $k_{0}$ as mentioned above, the threshold ( $\left.V_{\text {low }}\right)$ can be determined accordingly (Figure 10). In general, the trends of $V_{\text {low }}$ and $k_{0}$ against changes of $S_{0}$ and $G$ are the exact opposite. When $S_{0}$ or $G$ increases, $k_{0}$ will be larger (or at least not decrease because it is a positive integer), which means that the degree of EOC by investors will be severer. Since $V_{\text {low }}<0$, then $V_{\text {low }}$ will decline instead. From this perspective, the government guarantee is a critical issue and should be attributed considerable importance. When the government guarantee is at the appropriate level, the termination threshold ( $\left.V_{\text {low }}\right)$ for investors' EOC will remain 


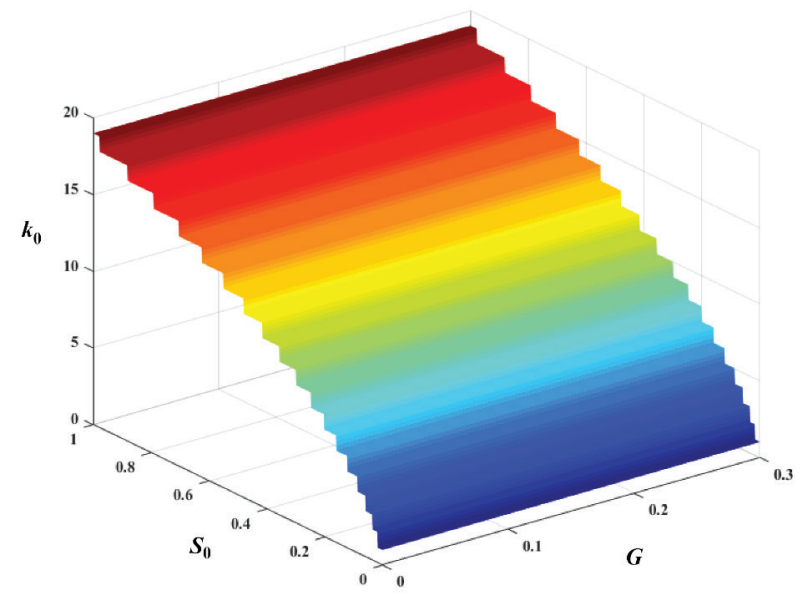

Figure 9. Relationship between $k_{0}, S_{0}$ and $G$

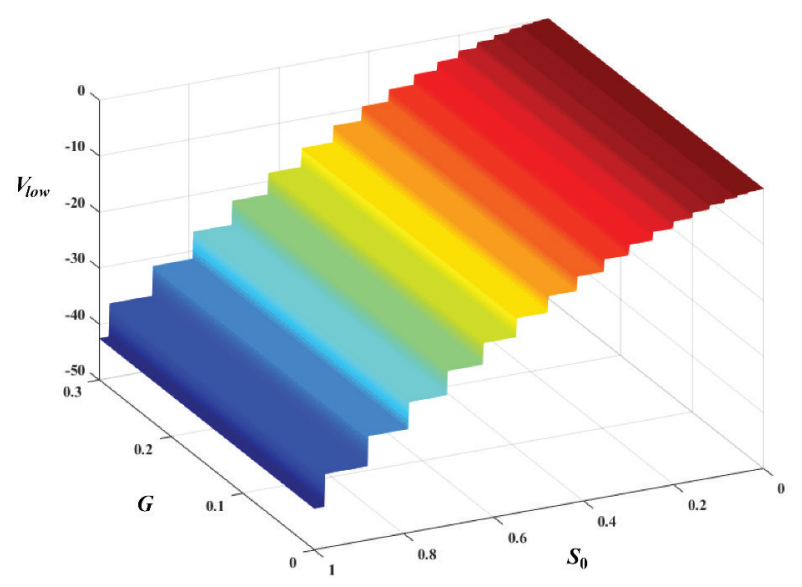

Figure 10. Relationship between $V_{\text {low }}, S_{0}$ and $G$

unchanged. However, excessive guarantees will not only increase the project value, including the expanded value (i.e., $V_{E O C}$ ), and delay the termination of the escalation but also aggravate the financial burden. As a result, governments should formulate a reasonable guarantee mechanism for EOC to effectively de-escalate commitment.

The numerical simulation further confirms that investors' generative cognition initially $\left(S_{0}\right)$ directly determines whether to terminate EOC to some extent. Consequently, when investing PPP projects by private investors, both governments and investors should agree on the project during negotiations, which ought to be specified in the contract, to collectively work toward creating a correct cognition of PPP projects. It is worth noting that when different values are assigned in the above models, the diagrams might change. The numerical example in this section only analyzes one possible hypothetical scenario to verify the effectiveness of the proposed models.

\section{Conclusions}

In PPP projects, investors often escalate the commitment in response to NF and generally presuppose a psychological threshold simultaneously. Once the losses from escalation reach this threshold, investors will terminate EOC and transfer projects to governments. The paper illustrates the maximum amount of NF acceptable to investors $\left(k_{0}\right)$ using the belief-adjustment model, followed by the analysis of the termination threshold $\left(V_{\text {low }}\right)$. By treating the investors' right to abandon PPP projects in an EOC scenario as a put option, the project value for investors' EOC $\left(V_{E O C}\right)$ is constructed using real option thinking. Different from the traditional real option method, the critical value discussed in the EOC scenario allows for some losses, i.e., the threshold is less than zero $\left(V_{\text {low }}<0\right)$. The results show that the threshold correlates with the initial generative cognition $\left(S_{0}\right)$, sunk cost level $\left(c_{k}\right)$, government guarantee degree $(G)$ and investors' behavioral preferences as well as with total investment $(I)$ and return on investment $(R)$. In such an escalation scenario, when the value of PPP projects is greater than the threshold, i.e., $V_{E O C} \geq V_{\text {low }}$, investors will persist in escalating their commitment. Conversely, if the value is less than the threshold, i.e., $V_{E O C}<V_{\text {low }}$, investors will terminate EOC and abandon the projects, thereby transferring them to governments to receive compensation or the residual asset value.

Since EOC causes losses for investors and governments and is not conducive to the sustainable development of PPP schemes, both parties should utilize appropriate means to de-escalate commitment. Total investment ( $I$ ) should be accurately estimated, and the return on investment $(R)$ should be negotiated to ensure reasonableness. For private investors, it is not always the case that a higher expected return on investment $(R)$ is better; a higher $R$ could increase the range of $\left|V_{\text {low }}\right|$ and further increase project losses. During negotiations over PPP projects, both governments and investors should agree on the project $\left(S_{0}\right)$ that should be specified in the contract in as much detail as possible to collectively work toward creating a correct understanding of PPP projects. Moreover, improving the evidentiary weight of NF $\left(a_{k}\right)$, by for example shortening the cycle for gathering information and improving the accuracy and transparency of project information feedback, is an effective measure for efficiently intervening in EOC.

In summary, by considering managerial behavior and resolving barriers to ensuring that investors make their decisions from a rational and probabilistic perspective, the contributions of this paper are to incorporate the subjective escalation behavior of investors into PPP projects and further to move beyond the standard of real option method by allowing the threshold to be less than zero in the EOC scenario. Finally, the limitations should be highlighted. First, the purpose of the numerical example presented in this article is to describe the proposed model 
more intuitively and verify its effectiveness. Due to the confidentiality of data in PPP projects, first-hand data on some actual PPP projects are not available and thus cannot be quantified to conduct case study. More importantly, the numerical example only analyzes one possible hypothetical scenario because the behavioral preferences of private investors are difficult to observe at this stage. Potentially, with the development of management, psychology and behavioral economics as well as advanced technology, such behavioral preferences will be captured quite comprehensively and precisely. Such analysis can be considered in future research. Still, the findings in this paper yield new insights for efficient governance to help governments deescalate investors' commitment in PPP projects.

\section{Funding}

This work was supported by the National Natural Science Foundation of China under Grant [number 71571149].

\section{Disclosure statement}

The authors declared that they have no conflict of interest.

\section{References}

Almassi, A., McCabe, B., \& Thompson, M. (2012). Real optionsbased approach for valuation of government guarantees in public-private partnerships. Journal of Infrastructure Systems, 19(2), 196-204.

https://doi.org/10.1061/(ASCE)IS.1943-555X.0000117

Aretz, K., \& Pope, P. F. (2018). Real options models of the firm, capacity overhang, and the cross section of stock returns. Journal of Finance, 73(3), 1363-1415. https://doi.org/10.1111/jofi.12617

Ashuri, B., Kashani, H., Molenaar, K. R., Lee, S., \& Lu, J. (2011). Risk-neutral pricing approach for evaluating BOT highway projects with government minimum revenue guarantee options. Journal of Construction Engineering and Management, 138(4), 545-557.

https://doi.org/10.1061/(ASCE)CO.1943-7862.0000447

Attarzadeh, M., Chua, D. K., Beer, M., \& Abbott, E. L. (2017). Options-based negotiation management of PPP-BOT infrastructure projects. Construction Management and Economics, 35(11-12), 676-692.

https://doi.org/10.1080/01446193.2017.1325962

Berg, J. E., Dickhaut, J. W., \& Kanodia, C. (2009). The role of information asymmetry in escalation phenomena: empirical evidence. Journal of Economic Behavior and Organization, 69(2), 135-147. https://doi.org/10.1016/j.jebo.2007.07.007

Biygautane, M., Neesham, C., \& Al-Yahya, K. O. (2019). Institutional entrepreneurship and infrastructure public-private partnership (PPP): unpacking the role of social actors in implementing PPP projects. International Journal of Project Management, 37(1), 192-219.

https://doi.org/10.1016/j.ijproman.2018.12.005

Bloom, N. (2009). The impact of uncertainty shocks. Econometrica, 77(3), 623-685. https://doi.org/10.3982/ECTA6248

Bobocel, D. R., \& Meyer, J. P. (1994). Escalating commitment to a failing course of action: separating the roles of choice and justification. Journal of Applied Psychology, 79(3), 360-363. https://doi.org/10.1037/0021-9010.79.3.360

Boulding, W., Guha, A., \& Staelin, R. (2016). Do we really need to change the decision maker? Counterintuitive escalation of commitment results in real options contexts. Management Science, 63(10), 3459-3472.

https://doi.org/10.1287/mnsc.2016.2475

Brandão, L. E., Bastian-Pinto, C., Gomes, L. L., \& Labes, M. (2012). Government supports in public-private partnership contracts: Metro Line 4 of the Sao Paulo Subway System. Journal of Infrastructure Systems, 18(3), 218-225. https://doi.org/10.1061/(ASCE)IS.1943-555X.0000095

Brockner, J. (1992). The escalation of commitment to a failing course of action: toward theoretical progress. Academy of Management Review, 17(1), 39-61.

https://doi.org/10.5465/amr.1992.4279568

Brouthers, K. D., \& Dikova, D. (2010). Acquisitions and real options: the greenfield alternative. Journal of Management Studies, 47(6), 1048-1071. https://doi.org/10.1111/j.1467-6486.2009.00875.x

Buyukyoran, F., \& Gundes, S. (2018). Optimized real optionsbased approach for government guarantees in PPP toll road projects. Construction Management and Economics, 36(4), 203-216. https://doi.org/10.1080/01446193.2017.1347267

Carbonara, N., \& Pellegrino, R. (2018). Revenue guarantee in public-private partnerships: a win-win model. Construction Management and Economics, 36(10), 584-598. https://doi.org/10.1080/01446193.2018.1467028

Carbonara, N., \& Pellegrino, R. (2019). The role of public private partnerships in fostering innovation. Construction Management and Economics, 38(2), 140-1561.

https://doi.org/10.1080/01446193.2019.1610184

Chung, S. H., \& Cheng, K. C. (2018). How does cognitive dissonance influence the sunk cost effect? Psychology Research and Behavior Management, 11, 37-45. https://doi.org/10.2147/PRBM.S150494

Collan, M., Haahtela, T., \& Kyläheiko, K. (2016). On the usability of real option valuation model types under different types of uncertainty. International Journal of Business Innovation and Research, 11(1), 18-37. https://doi.org/10.1504/IJBIR.2016.077608

Cruz, C. O., \& Marques, R. C. (2013). Flexible contracts to cope with uncertainty in public-private partnerships. International Journal of Project Management, 31(3), 473-483. https://doi.org/10.1016/j.ijproman.2012.09.006

Dahan, E., \& Mendelson, H. (2001). An extreme-value model of concept testing. Management Science, 47(1), 102-116. https://doi.org/10.1287/mnsc.47.1.102.10666

Drummond, H. (2014). Escalation of commitment: when to stay the course? Academy of Management Perspectives, 28(4), 430-446. https://doi.org/10.5465/amp.2013.0039

Feldman, G., \& Wong, K. F. E. (2018). When action-inaction framing leads to higher escalation of commitment: a new inaction-effect perspective on the sunk-cost fallacy. Psychological Science, 29(4), 537-548. https://doi.org/10.1177/0956797617739368

Feng, Z., Zhang, S. B., \& Gao, Y. (2015). Modeling the impact of government guarantees on toll charge, road quality and capacity for Build-Operate-Transfer (BOT) road projects. Transportation Research Part A: Policy and Practice, 78, 5467. https://doi.org/10.1016/j.tra.2015.05.006

Festinger, L. (1962). A theory of cognitive dissonance (Vol. 2). Stanford University Press. 
Galera, A. L. L., \& Soliño, A. S. (2010). A real options approach for the valuation of highway concessions. Transportation Science, 44(3), 416-427. https://doi.org/10.1287/trsc.1090.0299

Garvin, M. J., \& Ford, D. N. (2012). Real options in infrastructure projects: theory, practice and prospects. Engineering Project Organization Journal, 2(1-2), 97-108.

https://doi.org/10.1080/21573727.2011.632096

Guo, K., Zhang, L., \& Wang, T. (2019). Optimal scheme in energy performance contracting under uncertainty: a real option perspective. Journal of Cleaner Production, 231, 240-253. https://doi.org/10.1016/j.jclepro.2019.05.218

Hafenbrädl, S., \& Woike, J. K. (2018). Competitive escalation and interventions. Journal of Behavioral Decision Making, 31(5), 695-714. https://doi.org/10.1002/bdm.2084

Heath, C. (1995). Escalation and de-escalation of commitment in response to sunk costs: the role of budgeting in mental accounting. Organizational Behavior and Human Decision Processes, 62(1), 38-54. https://doi.org/10.1006/obhd.1995.1029

Herder, P. M., de Joode, J., Ligtvoet, A., Schenk, S., \& Taneja, P. (2011). Buying real options-valuing uncertainty in infrastructure planning. Futures, 43(9), 961-969.

https://doi.org/10.1016/j.futures.2011.06.005

Hogarth, R. M., \& Einhorn, H. J. (1992). Order effects in belief updating: the belief-adjustment model. Cognitive Psychology, 24(1), 1-55. https://doi.org/10.1016/0010-0285(92)90002-J

Hsieh, K. Y., Tsai, W., \& Chen, M. J. (2015). If they can do it, why not us? Competitors as reference points for justifying escalation of commitment. Academy of Management Journal, 58(1), 38-58. https://doi.org/10.5465/amj.2011.0869

Iossa, E., Spagnolo, G., \& Vellez, M. (2007). Best practices on contract design in public-private partnerships (Working Paper). World Bank.

Jani, A. (2008). An experimental investigation of factors influencing perceived control over a failing IT project. International Journal of Project Management, 26(7), 726-732. https://doi.org/10.1016/j.ijproman.2008.06.004

Jani, A. (2011). Escalation of commitment in troubled IT projects: influence of project risk factors and self-efficacy on the perception of risk and the commitment to a failing project. International Journal of Project Management, 29(7), 934-945. https://doi.org/10.1016/j.ijproman.2010.08.004

Jeong, J., Ji, C., Hong, T., \& Park, H. S. (2015). Model for evaluating the financial viability of the BOT project for highway service areas in South Korea. Journal of Management in Engineering, 32(2), 04015036. https://doi.org/10.1061/(ASCE)ME.1943-5479.0000396

Kahneman, D., \& Tversky, A. (1979). Prospect theory: an analysis of decision under risk. Econometrica: Journal of the Econometric Society, 263-291. https://doi.org/10.1142/9789814417358_0006

Karlsson, N., Gärling, T., \& Bonini, N. (2005). Escalation of commitment with transparent future outcomes. Experimental Psychology, 52(1), 67-73.

https://doi.org/10.1027/1618-3169.52.1.67

Keil, M., Rai, A., Mann, J. C., \& Zhang, G. P. (2003). Why software projects escalate: the importance of project management constructs. IEEE Transactions on Engineering Management, 50(3), 251-261. https://doi.org/10.1109/TEM.2003.817312

Keil, M., Tan, B. C., Wei, K. K., Saarinen, T., Tuunainen, V., \& Wassenaar, A. (2000). A cross-cultural study on escalation of commitment behavior in software projects. MIS Quarterly, 24(2), 299-325. https://doi.org/10.2307/3250940

Keil, M., Truex, D. P., \& Mixon, R. (1995). The effects of sunk cost and project completion on information technology pro- ject escalation. IEEE Transactions on Engineering Management, 42(4), 372-381. https://doi.org/10.1109/17.482086

Kiesler, C. A. (1971). The psychology of commitment: experiments linking behavior to belief. Academic Press.

Krüger, N. A. (2012). To kill a real option-incomplete contracts, real options and PPP. Transportation Research Part A: Policy and Practice, 46(8), 1359-1371. https://doi.org/10.1016/j.tra.2012.04.009

Ku, G., Malhotra, D., \& Murnighan, J. K. (2005). Towards a competitive arousal model of decision-making: a study of auction fever in live and Internet auctions. Organizational Behavior and Human Decision Processes, 96(2), 89-103.

https://doi.org/10.1016/j.obhdp.2004.10.001

Lee, J. S., Keil, M., \& Wong, K. F. E. (2018). Does a tired mind help avoid a decision bias? The effect of ego depletion on escalation of commitment. Applied Psychology, 67(1), 171-185. https://doi.org/10.1111/apps.12109

Li, S., Abraham, D., \& Cai, H. (2017). Infrastructure financing with project bond and credit default swap under public-private partnerships. International Journal of Project Management, 35(3), 406-419.

https://doi.org/10.1016/j.ijproman.2017.01.005

Liu, J., Gao, R., \& Cheah, Y. J. (2017). Pricing mechanism of early termination of PPP projects based on real option theory. Journal of Management in Engineering, 33(6), 04017035.

https://doi.org/10.1061/(ASCE)ME.1943-5479.0000556

Liu, J., Liu, J., Gao, R., Gao, H. O., \& Li, Y. (2019a). Identifying project factors that affect an investor's escalation of commitment in public-private partnership projects. Project Management Journal, 50(6), 686-698.

https://doi.org/10.1177/8756972819847874

Liu, J., Yu, X., \& Cheah, C. Y. J. (2014). Evaluation of restrictive competition in PPP projects using real option approach. International Journal of Project Management, 32(3), 473-481. https://doi.org/10.1016/j.ijproman.2013.07.007

Liu, S., Jin, H., Liu, C., Xie, B., \& Mills, A. (2019b). Government compensation and costs of non-competition guarantee for PPP rental retirement villages. Engineering, Construction and Architectural Management, 27(1), 128-149.

https://doi.org/10.1108/ECAM-01-2019-0063

Martins, J., Marques, R. C., \& Cruz, C. O. (2013). Real options in infrastructure: revisiting the literature. Journal of Infrastructure Systems, 21(1), 04014026.

https://doi.org/10.1061/(ASCE)IS.1943-555X.0000188

Marzouk, M., \& Ali, M. (2018). Mitigating risks in wastewater treatment plant PPPs using minimum revenue guarantee and real options. Utilities Policy, 53, 121-133.

https://doi.org/10.1016/j.jup.2018.06.012

McCain, B. E. (1986). Continuing investment under conditions of failure: a laboratory study of the limits to escalation. Journal of Applied Psychology, 71(2), 280-284.

http://doi.org/10.1037/0021-9010.71.2.280

Montealegre, R., \& Keil, M. (2000). De-escalating information technology projects: lessons from the Denver International Airport. MIS Quarterly, 24(3), 417-447.

http://doi.org/10.2307/3250968

Moon, H. (2001). Looking forward and looking back: integrating completion and sunk-cost effects within an escalation-ofcommitment progress decision. Journal of Applied Psychology, 86(1), 104-113. https://doi.org/10.1037//0021-9010.86.1.104

Moon, H., Conlon, D. E., Humphrey, S. E., Quigley, N., Devers, C. E., \& Nowakowski, J. M. (2003a). Group decision process and incrementalism in organizational decision making. Organizational Behavior and Human Decision Processes, 92(1-2), 67-79. https://doi.org/10.1016/S0749-5978(03)00079-7 
Moon, H., Hollenbeck, J. R., Humphrey, S. E., \& Maue, B. (2003b). The tripartite model of neuroticism and the suppression of depression and anxiety within an escalation of commitment dilemma. Journal of Personality, 71(3), 347-368. https://doi.org/10.1111/1467-6494.7103004

Morreale, A., Robba, S., Nigro, G. L., \& Roma, P. (2017). A real options game of alliance timing decisions in biopharmaceutical research and development. European Journal of Operational Research, 261(3), 1189-1202.

https://doi.org/10.1016/j.ejor.2017.03.025

Nunes, C., \& Pimentel, R. (2017). Analytical solution for an investment problem under uncertainties with shocks. European Journal of Operational Research, 259(3), 1054-1063. https://doi.org/10.1016/j.ejor.2017.01.008

Oh, H., \& Yoon, C. (2020). Time to build and the real-options channel of residential investment. Journal of Financial Economics, 135(1), 255-269.

https://doi.org/10.1016/j.jfineco.2018.10.019

Osei-Kyei, R., \& Chan, A. P. (2018). Stakeholders' perspectives on the success criteria for public-private partnership projects. International Journal of Strategic Property Management, 22(2), 131-142. https://doi.org/10.3846/ijspm.2018.444

Pan, G., \& Pan, S. L. (2011). Transition to IS project de-escalation: an exploration into management executives' influence behaviors. IEEE Transactions on Engineering Management, 58(1), 109-123. https://doi.org/10.1109/TEM.2010.2048908

Pan, G., Pan, S. L., \& Newman, M. (2009). Managing information technology project escalation and de-escalation: an approach-avoidance perspective. IEEE Transactions on Engineering Management, 56(1), 76-94.

https://doi.org/10.1109/TEM.2008.922638

Pan, S. L., Pan, G. S., Newman, M., \& Flynn, D. (2006). Escalation and de-escalation of commitment to information systems projects: insights from a project evaluation model. European Journal of Operational Research, 173(3), 1139-1160. https://doi.org/10.1016/j.ejor.2005.07.009

Pellegrino, R., Carbonara, N., \& Costantino, N. (2019). Public guarantees for mitigating interest rate risk in PPP projects. Built Environment Project and Asset Management, 9(2), 248261. https://doi.org/10.1108/BEPAM-01-2018-0012

Ross, J., \& Staw, B. M. (1993). Organizational escalation and exit: lessons from the Shoreham nuclear power plant. Academy of Management Journal, 36(4), 701-732.

https://doi.org/10.5465/256756

Rutten, M. E., Dorée, A. G., \& Halman, J. I. (2014). Together on the path to construction innovation: yet another example of escalation of commitment? Construction Management and Economics, 32(7-8), 695-704. https://doi.org/10.1080/01446193.2014.933855

Sarangee, K. R., Schmidt, J. B., \& Calantone, R. J. (2019). Anticipated regret and escalation of commitment to failing, new product development projects in business markets. Industrial Marketing Management, 76, 157-168.

https://doi.org/10.1016/j.indmarman.2018.08.008

Schaumberg, R. L., \& Wiltermuth, S. S. (2014). Desire for a positive moral self-regard exacerbates escalation of commitment to initiatives with prosocial aims. Organizational Behavior and Human Decision Processes, 123(2), 110-123. https://doi.org/10.1016/j.obhdp.2013.10.012

Sleesman, D. J., Conlon, D. E., McNamara, G., \& Miles, J. E. (2012). Cleaning up the big muddy: a meta-analytic review of the determinants of escalation of commitment. Academy of Management Journal, 55(3), 541-562.

https://doi.org/10.5465/amj
Sleesman, D. J., Lennard, A. C., McNamara, G., \& Conlon, D. E. (2018). Putting escalation of commitment in context: a multilevel review and analysis. Academy of Management Annals, 12(1), 178-207. https://doi.org/10.5465/annals.2016.0046

Song, J., Song, D., \& Zhang, D. (2015). Modeling the concession period and subsidy for B waste-to-energy incineration projects. Journal of Construction Engineering and Management, 141(10), 04015033.

https://doi.org/10.1061/(ASCE)CO.1943-7862.0001005

Song, J., Hu, Y., \& Feng, Z. (2018). Factors influencing early termination of PPP projects in China. Journal of Management in Engineering, 34(1), 05017008. https://doi.org/10.1061/(ASCE)ME.1943-5479.0000572

Staats, B. R., Kc, D. S., \& Gino, F. (2018). Maintaining beliefs in the face of negative news: the moderating role of experience. Management Science, 64(2), 804-824.

https://doi.org/10.1287/mnsc.2016.2640

Staw, B. M. (1976). Knee-deep in the big muddy: a study of escalating commitment to a chosen course of action. Organizational Behavior and Human Performance, 16(1), 27-44. https://doi.org/10.1016/0030-5073(76)90005-2

Staw, B. M. (1981). The escalation of commitment to a course of action. Academy of Management Review, 6(4), 577-587. https://doi.org/10.5465/amr.1981.4285694

Staw, B. M., \& Ross, J. (1987). Behavior in escalation situations: antecedents, prototypes and solutions. Research in Organizational Behavior, 9(4), 39-78. https://doi.org/10.1108/eb055578

Staw, B. M., \& Ross, J. (1989). Understanding behavior in escalation situations. Science, 246(4927), 216-220. https://doi.org/10.1126/science.246.4927.216

Tan, B. C., Smith, H. J., Keil, M., \& Montealegre, R. (2003). Reporting bad news about software projects: impact of organizational climate and information asymmetry in an individualistic and a collectivistic culture. IEEE Transactions on Engineering Management, 50(1), 64-77. https://doi.org/10.1109/TEM.2002.808292

Tang, Y., \& Liu, Z. (2008). Decision responsibility, generative cognition, escalation of commitment in capital budgeting decision: an experimental research based on role-playing experiments. Nankai Business Review, (1), 45-48.

Triantis, A. (2005). Realizing the potential of real options: does theory meet practice? Journal of Applied Corporate Finance, 17(2), 8-16. https://doi.org/10.1111/j.1745-6622.2005.00028.x

Trigeorgis, L., \& Tsekrekos, A. E. (2018). Real options in operations research: a review. European Journal of Operational Research, 270(1), 1-24.

https://doi.org/10.1016/j.ejor.2017.11.055

Tversky, A., \& Kahneman, D. (1992). Advances in prospect theory: cumulative representation of uncertainty. Journal of Risk and Uncertainty, 5(4), 297-323.

https://doi.org/10.1007/BF00122574

Valipour, A., Yahaya, N., Noor, N. M., Valipour, I., \& Tamošaitiene, J. (2019). A SWARA-COPRAS approach to the allocation of risk in water and sewerage public-private partnership projects in Malaysia. International Journal of Strategic Property Management, 23(4), 269-283. https://doi.org/10.3846/ijspm.2019.8066

Villani, E., Greco, L., \& Phillips, N. (2017). Understanding value creation in public-private partnerships: a comparative case study. Journal of Management Studies, 54(6), 876-905. https://doi.org/10.1111/joms.12270

Vroom, V. (1964). Expectancy theory. Work and motivation. Wiley. 
Wang, Y., Cui, P., \& Liu, J. (2018). Analysis of the risk-sharing ratio in PPP projects based on government minimum revenue guarantees. International Journal of Project Management, 36(6), 899-909.

https://doi.org/10.1016/j.ijproman. 2018.01.007

Wang, Y., Gao, H. O., \& Liu, J. (2019). Incentive game of investor speculation in PPP highway projects based on the government minimum revenue guarantee. Transportation Research Part A: Policy and Practice, 125, 20-34. https://doi.org/10.1016/j.tra.2019.05.006

Wang, Y., \& Liu, J. (2015). Evaluation of the excess revenue sharing ratio in PPP projects using principal-agent models. International Journal of Project Management, 33(6), 1317-1324. https://doi.org/10.1016/j.ijproman.2015.03.002

Westfall, J. E., Jasper, J. D., \& Christman, S. (2012). Inaction inertia, the sunk cost effect, and handedness: avoiding the losses of past decisions. Brain and Cognition, 80(2), 192-200. https://doi.org/10.1016/j.bandc.2012.06.003

Whyte, G. (1986). Escalating commitment to a course of action: a reinterpretation. Academy of Management Review, 11(2), 311-321. https://doi.org/10.5465/amr.1986.4283111

Winch, G. M. (2013). Escalation in major projects: lessons from the Channel Fixed Link. International Journal of Project Management, 31(5), 724-734. https://doi.org/10.1016/j.ijproman.2013.01.012

Wong, K. F. E. (2005). The role of risk in making decisions under escalation situations. Applied Psychology, 54(4), 584-607. https://doi.org/10.1111/j.1464-0597.2005.00236.x

Wong, K. F. E., \& Kwong, J. Y. (2007). The role of anticipated regret in escalation of commitment. Journal of Applied Psychology, 92(2), 545-554.

https://doi.org/10.1037/0021-9010.92.2.545
Wong, K. F. E., \& Kwong, J. Y. (2018). Resolving the judgment and decision-making paradox between adaptive learning and escalation of commitment. Management Science, 64(4), 19111925. https://doi.org/10.1287/mnsc. 2016.2686

Wong, K. F. E., Kwong, J. Y. Y., \& Ng, C. K. (2008). When thinking rationally increases biases: the role of rational thinking style in escalation of commitment. Applied Psychology, 57(2), 246-271. https://doi.org/10.1111/j.1464-0597.2007.00309.x

Xiong, W., Zhang, X., \& Chen, H. (2015). Early-termination compensation in public-private partnership projects. Journal of Construction Engineering and Management, 142(4), 04015098. https://doi.org/10.1061/(ASCE)CO.1943-7862.0001084

Yao, X., Fan, Y., Xu, Y., Zhang, X., Zhu, L., \& Feng, L. (2019). Is it worth to invest? - An evaluation of CTL-CCS project in China based on real options. Energy, 182(1), 920-931. https://doi.org/10.1016/j.energy.2019.06.100

Yu, S., Li, Z., Wei, Y. M., \& Liu, L. (2019). A real option model for geothermal heating investment decision making: considering carbon trading and resource taxes. Energy, 189, 116252. https://doi.org/10.1016/j.energy.2019.116252

Zapata Quimbayo, C. A., Mejía Vega, C. A., \& Marques, N. L. (2019). Minimum revenue guarantees valuation in PPP projects under a mean reverting process. Construction Management and Economics, 37(3), 121-138. https://doi.org/10.1080/01446193.2018.1500024

Zardkoohi, A. (2004). Do real options lead to escalation of commitment? Academy of Management Review, 29(1), 111-119. https://doi.org/10.5465/amr.2004.11851733

Zhang, G. P., Keil, M., Rai, A., \& Mann, J. (2003). Predicting information technology project escalation: a neural network approach. European Journal of Operational Research, 146(1), 115-129. https://doi.org/10.1016/S0377-2217(02)00294-1 